https://helda.helsinki.fi

\title{
Leaf carbon and water status control stomatal and nonstomatal limitations of photosynthesis in trees
}

\section{Salmon, Yann}

2020-05

Salmon , Y , Lintunen , A , Dayet , A , Chan , T , Dewar , R , Vesala , T \& Holtta , T 2020 , ' Leaf carbon and water status control stomatal and nonstomatal limitations of photosynthesis in trees ' , New Phytologist, vol. 226 , no. 3 , pp. 690-703 . https://doi.org/10.1111/nph.16436

http://hdl.handle.net/10138/324758

https://doi.org/10.1111/nph.16436

acceptedVersion

Downloaded from Helda, University of Helsinki institutional repository.

This is an electronic reprint of the original article.

This reprint may differ from the original in pagination and typographic detail.

Please cite the original version. 


\section{${ }_{1}$ Leaf carbon and water status control stomatal and non-stomatal 2limitations of photosynthesis in trees.}

3

4

5Yann Salmon ${ }^{1,2}$ *, Anna Lintunen², Alexia Dayet ${ }^{2}$, Tommy Chan ${ }^{1,2}$, Roderick Dewar ${ }^{3}$, Timo 6Vesala ${ }^{1,2}$, Teemu Hölttä ${ }^{2}$

7

$8^{1}$ Institute for Atmospheric and Earth System Research / Physics, Faculty of Science, P.O. Box 68, 9Gustaf Hällströmin katu 2b, 00014 University of Helsinki, Finland

$10^{2}$ Institute for Atmospheric and Earth System Research / Forest Sciences, Faculty of Agriculture and 11Forestry, Latokartanonkaari 7, P.O. Box 27, 00014 University of Helsinki, Finland

$12^{3}$ Research School of Biology, The Australian National University, Canberra ACT 2601, Australia

13*corresponding author: yann.salmon@helsinki.fi

14Words: 5570

15Introduction: 1378

16Material and methods: 1930

17Results: 865

18Discussion and conclusion: 1397

19Figures (colour): 6

20Figure (black and white): 2

21Table: 3

22Supplementary material is provided 


\section{Summary}

- Photosynthetic rate is concurrently limited by stomatal and non-stomatal limitations.

25 However, the controls on non-stomatal limitations to photosynthesis (NSL) and their 26 coordination with stomatal control on different timescales remain poorly understood.

27 According to a recent optimization hypothesis, NSL depends on leaf osmotic or water status,

28 and is coordinated with stomatal control so as to maximize leaf photosynthesis.

29 - Drought and notching experiments were conducted on Pinus sylvestris, Picea abies, Betula

30 Pendula, and Populus tremula seedlings in greenhouse conditions to study the dependence

31 of NSL on leaf osmotic and water status, and its coordination with stomatal control, on 32 timescales of minutes and weeks, to test the assumptions and predictions of the optimization 33 hypothesis.

34 - Both NSL and stomatal conductance followed power-law functions of leaf osmotic 35 concentration and leaf water potential. Moreover, stomatal conductance was proportional to 36 the square root of soil-to-leaf hydraulic conductance, as predicted by the optimization 37 hypothesis.

- While the detailed mechanisms underlying the dependence of NSL on leaf osmotic or water status lie outside the scope of this study, our results support the hypothesis that NSL and stomatal control are coordinated to maximize leaf photosynthesis, and allow the effect of NSL to be included in models of tree gas-exchange.

42Key words: Drought, leaf osmotic concentration, notching, stomatal conductance, xylem transport, 43leaf water potential, non-stomatal limitation.

44

\section{Introduction}

46

47Leaf photosynthesis is subject to both stomatal and non-stomatal limitations (hereafter NSL) 48(Buckley \& Diaz-Espejo, 2015). Stomatal limitations refer to restrictions in the supply of $\mathrm{CO}_{2}$ by 49diffusion through the stomata to the intercellular spaces within leaves. Non-stomatal limitations 50refer to all other processes limiting the rate of leaf photosynthesis; these include the diffusion of $51 \mathrm{CO}_{2}$ from the leaf-intercellular spaces to the sites of the dark reactions of photosynthesis in 52chloroplasts (i.e. a finite mesophyll conductance), and biochemical limitations to photosynthetic 53efficiency (Grassi \& Magnani, 2005). 
55Generally, stomatal and non-stomatal limitations to photosynthesis operate concurrently and are 56coordinated with each other (Flexas et al., 2008; Gago et al., 2016). For example, both limitations 57occur during drought (Drake et al., 2017) when soil water availability decreases and/or vapour 58pressure deficit (VPD) increases. While it has long been recognized that stomata react rapidly to 59environmental changes (Jarvis et al., 1976) and internal leaf water status (Sperry et al., 1993), more 60recently it has become evident that NSL also operate on the same time scale as stomatal limitations 61(Flexas et al., 2008; Flexas et al., 2012; Kaiser et al., 2015). However, what is lacking is a 62quantitative understanding of the controls on NSL and their co-ordination with stomatal limitation. 63Such an understanding is central to our ability to predict adaptive responses of plants to climate 64change, such as increased drought (McDowell et al., 2011; Choat et al., 2012; Klein \& Hartmann, 652018).

66

67Recently it has been conjectured that co-ordination of stomatal and non-stomatal limitations to 68photosynthesis might be understood from the viewpoint of maximizing net leaf photosynthetic rate 69(A) within a whole-tree level framework (Hölttä et al., 2017) that also involves co-ordination 70between sugar source, transport and sink processes. Because sugar accumulation in mesophyll cells 71is tightly coupled to sugar export by the phloem (Nikinmaa et al., 2013), especially in passive 72loading species (Turgeon, 2010), this conjecture is also closely related to the one of maximizing 73phloem transport (Nikinmaa et al., 2013; Huang et al., 2018). According to this hypothesis, as 74stomatal conductance $\left(g_{s}\right)$ increases (under constant environmental conditions) there is a tradeoff 75between increases in $A$ through increased leaf-intercellular $\mathrm{CO}_{2}$ concentration $\left(c_{i}\right)$, and decreases in 76A through NSL associated with decreased leaf water potential (Dewar et al., 2018) and/or an 77associated increase in leaf sugar concentration (a potential mechanism in presented in box 1) as 78observed in numerous species (Jeannette et al., 2000; e.g., Turnbull et al., 2002; Franck et al., 2006; 79Hüve et al., 2006; Quentin et al., 2013; Cano et al., 2014; Kelly et al., 2014; Ramalho et al., 2014; 80Kitao et al., 2015; Hölttä et al., 2017). As a result, there is a maximum in the $A-g_{s}$ curve at which 81stomatal and non-stomatal limitations to photosynthesis are in balance. If the stomata would open 82further from their optimal opening rate, internal $\mathrm{CO}_{2}$ concentration would increase, thus increase the 83supply of $\mathrm{CO}_{2}$, but at the same time, the increasing water loss rate by transpiration would decrease 84leaf water potential and increase osmotic concentration so that in the increase in non-stomatal 85limitations would lead to a decrease in gross assimilation rate (Fig. 1). Within this framework (Fig. 861), factors influencing stomatal limitation to photosynthesis include the maximum rates of 87carboxylation $\left(V_{\mathrm{cmax}}\right)$ and electron transport $\left(J_{\max }\right), \mathrm{CO}_{2}$ concentration and photosynthetically active 
88radiation (PAR). Factors influencing NSL to photosynthesis include VPD, soil water potential $\left(\Psi_{\mathrm{s}}\right)$ 89and soil-to-leaf hydraulic conductance $\left(K_{\mathrm{sl}}\right)$, with $K_{\mathrm{sl}}$ itself dependent on $\Psi_{\mathrm{s}}$ and on xylem 90 vulnerability characteristics (e.g. PLC 50 , the xylem water potential for $50 \%$ loss of conductance). In 91addition, NSL also respond to sugar transport as shown by its response to decreasing sink strength 92(Azcón-Bieto, 1983; Goldschmidt \& Huber, 1992; Nakano et al., 2000; Hölttä et al., 2017).

93This theoretical conjecture has led to several unique experimentally testable predictions that 94distinguish it from other models of stomatal conductance. For example, in the analytically solvable 95model of Dewar et al. (2018), in which non-stomatal limitation to photosynthesis is assumed to be 96linearly related to leaf water potential, and xylem embolism is ignored, the optimal stomatal 97conductance and photosynthetic rate are related by

98

$$
g_{s}=\frac{A}{c_{a}-\Gamma^{\dot{\iota}}}\left(1+\frac{\xi}{\sqrt{D}}\right) \text {, }
$$

99where $c_{a}$ is the atmospheric $\mathrm{CO}_{2}$ concentration, $\Gamma^{*}$ is the photorespiratory $\mathrm{CO}_{2}$ compensation point, $100 D$ is VPD, and $\xi$ is a simple combination of various physiological parameters of the model (Dewar 101et al., 2018, their table 4):

102

$$
\xi=\sqrt{\frac{K_{s l}\left|\psi_{c}\right|}{1.6}\left(r_{x, 0}+\frac{2 \Gamma^{i}}{\alpha_{0} Q}\right)},
$$

103where $\psi_{\mathrm{c}}$ is the critical leaf water potential, $r_{x, 0}$ is the carboxylation resistance in the absence of 104NSL, $\alpha_{0}$ is the photosynthetic quantum yield in the absence of NSL and Q is the leaf photosynthetic 105photon flux density. Mathematically, eqn (1) is almost identical in form to the relationship derived 106by Medlyn et al. (2011) from the alternative optimization hypothesis (Cowan \& Farquhar, 1977) 107that stomata maximize leaf photosynthesis for a given amount of leaf transpiration (rather than 108through a tradeoff between stomatal and non-stomatal limitations),

$$
g_{s}=g_{0}+\frac{A}{c_{a}}\left(1+\frac{g_{1}}{\sqrt{D}}\right),
$$

110in which $g_{0}$ and $g_{1}$ are empirical parameters ( $g_{1}$ is related to the marginal water cost of plant carbon 111gain); eqns (1) and (3) are identical when $g_{0}=0$ and $g_{1}=\xi$ in eqn (3) and $\Gamma^{*}=0$ in eqn (1). Both of 112these alternative optimization hypotheses successfully predict the observed close correlation 
113between $g_{s}$ and $A$ (Wong et al., 1979) that forms the basis of the empirical Ball-Woodrow-Berry 114stomatal model and its variants (Ball et al., 1987; Leuning, 1995).

116However, a key difference is that while $g_{1}$ in eqn (3) is a priori unknown and must be determined by 117fitting eqn (3) to data, $\xi$ in eqn (1) is fully determined as a function of measurable physiological 118parameters; in particular, $\xi$ is predicted to be proportional to $\sqrt{K_{s l}}$ (Dewar et al., 2018, their Table 1194). Thus, while eqn (3) successfully encapsulates the dependence of $g_{s}$ on all other factors shown in 120Fig. 1, it does not explicitly describe a dependence on $K_{s l}$, whereas numerous experiments have 121shown that stomatal conductance is positively related to hydraulic conductance (Sperry et al., 1993; 122Nardini \& Salleo, 2000). In contrast, eqn (1) predicts a positive relationship between $g_{s}$ and $K_{s l}$ via 123the parameter $\xi \propto \sqrt{K_{s l}}$, reflecting the role $K_{s l}$ plays in determining the extent of NSL through its 124influence on leaf water potential. In eqn (1) the term $\frac{\xi}{\sqrt{D}}$ tends to dominate the factor in brackets; 125with $\Gamma^{*} \approx 0$, eqn (1) then becomes

$$
g_{s} \approx \frac{A}{c_{a}} \frac{\xi}{\sqrt{D}} \propto \frac{A}{c_{a}} \sqrt{\frac{K_{s l}}{D}} .
$$

127Thus, all else being equal, $g_{s}$ is predicted to be proportional to $\sqrt{K_{s}}$, a result also found numerically 128from the model of Hölttä et al. (2017), which included xylem embolism, and which assumed that 129NSL was linearly related to leaf sugar concentration rather than leaf water potential. Indeed, an 130analytically solvable version of this sugar-based model, in which xylem embolism is ignored 131(Dewar \& Hölttä, unpublished), also leads to eqn (4), which therefore appears to be a robust 132prediction of the hypothesis that NSL and stomatal control are coordinated so as to maximize leaf 133photosynthesis

134However, the dependence of $g_{s}$ on $K_{s l}$ predicted by eqn (4) is yet untested, as are the underlying 135assumptions that non-stomatal limitations to photosynthesis are related to either leaf water status or 136leaf sugar status, and act on the same time scale as stomatal limitation. The overall objective of this 137study was to provide experimental tests of the conjecture that stomatal and non-stomatal limitations 138to photosynthesis are co-ordinated so as to maximize leaf photosynthetic rate (Fig. 1). The specific 139hypotheses were:

140 1) NSL increase with decreasing leaf water status and/or increasing leaf sugar/osmotic status;

141 2) These correlations are similar across timescale and species; 
142 3) NSL and stomatal limitation to photosynthesis are coordinated on similar time scales and for 143 different species;

144 4) The key model prediction of eqn (4), particularly with regard to its implication for the 145 relationship between $g_{s}$ and $K_{s l}$, is supported by experimental data

146To achieve these aims, we used saplings from four common boreal species (Pinus sylvestris, Picea 147abies, Populus tremula and Betula pendula) to conduct two experiments in which leaf water and 148sugar status were manipulated on different time scales: (i) a drought treatment to induce changes in 149photosynthetic rates over a time scale of weeks; and (ii) a notching experiment, where xylem 150hydraulic conductance was artificially reduced to induce changes in photosynthetic rates over a time 151scale of minutes/hours.

152

\section{Materials and Method}

154

155All experiments were performed at the greenhouse and laboratory facilities at the Viikki campus of 156the University of Helsinki (Helsinki, Finland).

157

158Drought experiment

159Potted saplings of Pinus sylvestris (L.), Picea abies (L. H. Karst.), Populus tremula (L.) and Betula 160pendula (Roth.) were used for this experiment. Aspen and birch were acclimated for five weeks, 161and pine and spruce were acclimated for four weeks to greenhouse conditions (PAR $800 \mu \mathrm{mol} \mathrm{m}{ }^{-2}$ $162 \mathrm{~s}^{-1}$, temperature $\sim 20^{\circ} \mathrm{C}$, relative humidity $\sim 55 \%$, ambient $\left[\mathrm{CO}_{2}\right] \sim 400 \mathrm{ppm}$ ) prior to the first 163measurements. Initial heights and diameters of the trees are shown in Table 1.

165During the experiment, all trees were kept in the greenhouse under stable environmental conditions. 166Two treatments were applied to the seedlings: (1) control, in which seedlings were automatically 167watered twice a day by flooding the table on which they were kept, and (2) drought, in which 168seedlings received no irrigation after the beginning of the experiment. The drought treatment started 169on the third week of April 2017.

\section{0}

171The following measurements were performed on two control saplings and three droughted saplings 172per week of sampling: leaf gas exchange under ambient conditions, $A-c_{i}$ and light curves, leaf water 173potential, and leaf osmotic concentration (see below for details). The weeks (W) of sampling for 174each species were as follows: 
176• Pine: W0, W2, W3, W5, W6

177• Spruce: W0, W2, W3, W4, W5

178• Aspen: W0, W1, W2

179• Birch: W0, W1, W2, W3

180

181The duration and frequency of measurements were decided based on a priori estimation of species 182drought sensitivity. On week 0,3 seedlings per species were sampled; these measurements 183correspond to background values.

184

185Notching experiment

186Potted saplings of four Pinus sylvestris, seven Populus tremula and six Betula pendula were used for 187this experiment. The seedlings were approximately 1 meter in height and $2 \mathrm{~cm}$ in diameter at the 188base. Measurements were made during three periods: spring 2015 for the pines, later summer and 189early autumn 2016 and late summer 2017 for the broadleaves. Measurements conducted for pine in 190the notching experiment have already been published (Hölttä et al., 2017).

191

192Seedlings were brought inside the laboratory three days prior to the measurements and were well 193watered. The seedlings were kept in constant environmental conditions (PAR $400 \mu \mathrm{mol} \mathrm{m}^{-2} \mathrm{~s}^{-1}$, 194temperature $\sim 22{ }^{\circ} \mathrm{C}$, VPD $~ 0.01 \mathrm{~mol} \mathrm{~mol}^{-1}$, ambient $\left[\mathrm{CO}_{2}\right] \sim 450 \mathrm{ppm}$ ) for 3 to 8 hours before the 195experiment. During the measurements, the saplings were notched at approximately $20 \mathrm{~cm}$ below the 196point of leaf gas exchange measurement to decrease xylem hydraulic conductance and induce rapid 197changes in leaf water and osmotic potentials, and leaf gas exchange. Notching was done by 198gradually cutting the stem xylem with a scalpel so that the xylem hydraulic conductance would 199decrease gradually (Sperry et al., 1993).

200

201Leaf gas exchange measurements

202Net $\mathrm{CO}_{2}$ assimilation rate or net photosynthetic rate $(A)$, stomatal conductance $\left(g_{s}\right)$ and transpiration 203rate $(E)$ were measured with a portable gas-exchange system (GFS-3000, Walz, Effeltrich, 204Germany). Leaf internal $\mathrm{CO}_{2}$ concentration $\left(c_{i}\right)$ was calculated by the portable gas-exchange 205system. For each seedling, after at least 15 min acclimation to darkness, dark respiration rate was 206measured for 5 minutes by measuring the $\mathrm{CO}_{2}$ efflux rate in the dark. Gross photosynthetic rate $(P)$ 207was then calculated as the sum of net $\mathrm{CO}_{2}$ assimilation rate and the 5-min averaged dark respiration 208rate. Prior to measurements, a leaf from the broad-leaved species and eight needles from the pine 
209were positioned inside a closed cuvette. Environmental conditions in the cuvette were set close to 210the ambient environment in the greenhouse (see above).

211

212For the drought experiment, measurements of leaf gas exchange were conducted under ambient 213conditions (see above), $\mathrm{CO}_{2}$ response curves (hereafter referred to as $A-c_{i}$ curves) were made with 214the following sequence of $\mathrm{CO}_{2}$ concentration (in ppm): 400, 200, 100, 50, 400, 600, 800, 1200. Four 215to five measurements were taken at each $\mathrm{CO}_{2}$ level; $A-c_{i}$ curves were then fitted using the 216PlantEcophys package in R (Duursma, 2015). We used the default assumption of this package that 217mesophyll conductance $\left(g_{m}\right)$ was infinite during the fitting of the $A-c_{i}$ curve, because setting a finite 218value of $g_{m}$ would have interfered with our goal of estimating non-stomatal limitation from actual 219measurements. As a result, the apparent maximum rate of carboxylation $V_{\text {cmax }}$ and the apparent 220electron transport rate $J_{\max }$ were extracted from the fitted $A-c_{i}$ curves. Therefore, changes in apparent $221 V_{\text {cmax }}$ and $J_{\max }$ reflect changes not only in biochemical limitation but also in $g_{m}$. For the notching 222experiment, leaf gas exchange was recorded every minute from prior to notching until the end of the 223experiment.

224

225A digital photograph of the leaves inside the cuvette was taken for estimating leaf area. The area 226covered by the leaf was calculated a posteriori with imageJ (Schneider et al., 2012). Original leaf 227gas exchange (obtained from setting the GFS-3000 to a leaf area of $1 \mathrm{~cm}^{2}$ ) data were then scaled 228using the measured leaf area using the GFS software (Walz). For pine and spruce, we assumed that 229the gas-exchange area was twice the projected area because both sides of the needles have stomata 230(As the needle surface are slightly curved rather that perfectly flat, the actual leaf area is likely to be 231slightly higher than twice the projected area. Thus, we are likely slightly overestimating the gas232exchange per area.).

233

234Because ambient $\mathrm{CO}_{2}$ concentration and light level were kept constant in our experiments, the ratio 235of $A$ to $C_{i}$ was used to evaluate changes in NSL. This procedure assumes a quasi-linear $A-c_{i}$ 236relationship, which is reasonable if changes in $c_{i}$ are small. To confirm the validity of using $A / c_{i}$ as a 237measure of NSL, we also evaluated NSL by comparing how much each value of $A$ measured during 238the notching experiment deviated from the $A-c_{i}$ curve measured before the notching, whenever this 239was possible (see Supplementary Materials Notes S1 and Fig. S1).

241 Osmotic concentration measurements 
242Leaf osmotic concentration $\left(\mathrm{mol} \mathrm{kg}^{-1}\right)$ is the sum of the concentrations of all dissolved solutes in 243leaf sap. Leaf osmotic concentration determines leaf osmotic potential, a component of leaf water 244potential, and is strongly influenced by leaf sugar status.

245

246In the drought experiment, leaves and needles were collected for leaf water potential and osmotic 247concentration measurements directly after the leaf gas exchange measurement. In the notching 248experiment, leaves and needles were collected several times during each experiment, the collection 249time being recorded and later matched with the gas exchange measurements. The collected leaves 250and needles were immediately frozen in liquid nitrogen in order to break cell membranes and 251release symplastic contents to the apoplast (Kikuta \& Richter, 1992; Callister et al., 2006). Osmotic 252concentration samples from the drought and notching experiment were either immediately 253processed or stored at $-80^{\circ} \mathrm{C}$. Prior to measurements, samples were allowed to thaw in a sealed 254plastic tube. Immediately after thawing (to avoid the degradation of di- and polysaccharides) the sap 255of the leaves or needles was extracted by either pressurizing them in a syringe (drought experiment; 256extraction was always performed by the same user applying maximum pressure to minimize 257artifacts) or by centrifuging (notching experiment) them at $14000 \mathrm{~g}$ for 10 minutes (Heraeus Fresco 25817 Centrifuge, Thermo Scientific, Massachusetts, USA). The collected liquid was measured with an 259osmometer (Osmomat-030 Freezing point osmometer, Gonotec, Berlin, DE) immediately after 260extraction to avoid water evaporation from the samples and microbial contamination.

261

262Leaf water potential and soil-to-leaf hydraulic conductance measurements

263Leaf water potential ( $\Psi_{\text {leaf, }}$ Pa) was measured with a pressure chamber (PMS-1000, PMS 264instruments, Albany, OR, USA). In the drought experiment, leaf water potential was measured for 265each seedling at pre-dawn $\left(\Psi_{\mathrm{PD}}\right)$ prior to any other destructive measurements, and immediately after 266the leaf gas exchange measurements. Because late spring and early summer nights in Helsinki 267(latitude $60.17^{\circ}$ ) are very short and saplings may have insufficient time to equilibrate hydraulically 268with the soil, the saplings were covered with black plastic bags for the whole night and $\Psi_{\text {PD }}$ was 269measured in the morning just before removing the bags.

\section{0}

271In the drought experiment, soil water potential $\left(\Psi_{\mathrm{s}}\right)$ was assumed equal to $\Psi_{\mathrm{PD}}$. In the notching 272experiment, sampling for measurements of leaf osmotic concentration and water potential were 273done simultaneously, and $\Psi_{\mathrm{s}}$ was assumed equal to zero as the soil was well-watered. Soil-to-leaf 274hydraulic conductance was then estimated as 


$$
K_{s l}=\frac{E}{\Delta \Psi},
$$

276where $\Delta \Psi(\mathrm{Pa})$ is the soil-to-leaf water potential difference ( $\Psi_{\mathrm{PD}}-\Psi_{\text {leaf }}$ for the drought experiment, $277-\Psi_{\text {leaf }}$ for the notching experiment).

278

279Testing the predicted relationship between $g_{s}$ and $K_{s l}$

280We used the experimental results to test eqn (4), the theoretical prediction of the optimization 281hypothesis, as follows. Because ambient $\mathrm{CO}_{2}$ concentration $\left(c_{a}\right)$ was kept constant, substitution of 282eqn (5) into eqn (4) gives

$$
g_{s} \propto \frac{A}{\sqrt{D}} \sqrt{\frac{E}{\Delta \Psi}} .
$$

284However, measurements of the two sides of eqn (6) are not independent, because $g_{s}$ on the left-hand 285side was calculated from measurements of $E$, which also appears on the right-hand side. However, 286by substituting $g_{s}=E / 1.6 D$ and re-arranging the resulting equation so that $E$ appears only on the 287left-hand side, eqn (6) may be re-expressed in the equivalent form (See note S3 for the details):

$$
E \propto A^{2} \frac{D}{\Delta \Psi} \equiv r
$$

289in which the left- and right-hand sides can be measured independently. We therefore tested the key 290prediction of the stomatal optimization model in the form of eqn (7); because this is a 291proportionality rather than an equality, for convenience, we compared the normalised value $r / r_{\max }$ to 292the measured value of $E$, where $r$ is the right-hand side of eqn (7) and $r_{\max }$ is the maximum value of $293 r$.

295Statistical analysis

296

297All statistical analyses were performed in R version 3.3.3 (R Core Team, 2017). Due to the different 298structure of the drought and notching experiments, they were analyzed separately using different 299methods.

300

301For the drought experiment, the dependences of $P, g_{\mathrm{s}}, P / c_{\mathrm{i}}, V_{\mathrm{cmax}}$ and $J_{\max }$ on leaf osmotic 302concentration and water potential were fitted to a power-law, using a linear model after logarithmic 303transformation of the data (see Table 2). The influence of VPD was tested as a covariate, and the 304fixed-effect variables of species and treatment (control and stressed) as well as their interaction 305were also added to the model. Similar methods were used to test the relations between: 1$) P / c_{i}$ and 
$306 g_{s}$ : the variables were log-transformed, leaf temperature was included as a covariate and species was 307included as a fixed effect in the model; 2) $r / r_{\max }$ and $E$ : no transformation was needed and species as 308a fixed effect.

309

310For the notching experiment, since several measurements were performed on each sapling 311following the treatment, a unique identifier for each sapling was assigned and used as a random 312term. Then, the effect of osmotic concentration and water potential on $P, g_{\mathrm{s}}$ and $P / c_{\mathrm{i}}$ were tested 313with a mixed-effect linear model (package nlme, Pinheiro et al., 2017), with logarithmic 314transformation of the data as required (see Table 3). The influence of leaf temperature on $P / c_{\mathrm{i}}$, and 315of VPD on $P$ and $g_{\mathrm{s}}$, were tested as covariates. Initially, the full model was tested with the effect of 316osmotic concentration or water potential, species, treatment and their interactions, and then the 317model was simplified when possible based on the AIC (Akaike information criterion). Model 318selection and testing were performed according to Zuur et al. (2009). The model with the lowest 319AIC that was not significantly different from the full model was then selected. Similar methods 320were used to test the relations between: 1) $P / c_{i}$ and $g_{s}$ : the variables were log-transformed, leaf 321temperature was included as a covariate and species was included as a fixed effect in the model; 2) $322 r / r_{\max }$ and $E$ : no transformation was needed and species as a fixed effect.

\section{Results}

325

326Leaf gas-exchange

328The drought treatment successfully created a wide range of values of leaf water potential and leaf 329osmotic concentration for the four species used in the experiment (Fig. 2). $P$ and $g_{\mathrm{s}}$ decreased with 330increasing leaf osmotic concentration (Fig 2A) and decreasing leaf water potential (Fig. 2B). The 331model with leaf osmotic concentration explained more of the variance than the model with leaf 332water potential (see model $\mathrm{R}^{2}$ values in Table 2. Note that the provided $\mathrm{R}^{2}$ is for the whole model 333and thus accounts for the influence of all explanatory variables such as species and treatment kept in 334the final model as described in Table 2). All the observed relations showed a significant effect of 335treatment (control versus stressed) and species, either independently or interactively (Tables 2 and 336S1, Figure 2). Power-law fits with species-average exponents of -3.43 and -3.47 were obtained for $337 P$ and $g_{\mathrm{s}}$ versus osmotic concentration, respectively, and -1.27 and -1.54 for $P$ and $g_{\mathrm{s}}$ versus leaf 338water potential respectively (see Table S1 for species specific values). 
340 Notching resulted in a decrease in leaf water potential, $P$ and $g_{\mathrm{s}}$, and an increase in leaf osmotic 341concentration in all species. $P$ and $g_{\mathrm{s}}$ decreased significantly (Table 3) with increasing leaf osmotic 342concentration (Fig. 3A and C) and decreasing leaf water potential (Fig. 3B and D). These relations 343followed a power-law fit with a species-average exponent of -2.16 for $P$ versus leaf osmotic 344concentration and -0.78 for $P$ versus leaf water potential; the species-average exponents for $g_{\mathrm{s}}$ 345versus osmotic concentration and $g_{\mathrm{s}}$ versus leaf water potential were -2.25 and -0.6 respectively (see 346Table S2 for species specific values). Species only had a significant effect on the relation between $347 g_{s}$ and leaf osmotic concentration (Table 3 and S2). Overall, in contrast to the drought experiment, 348changes in leaf water potential explained more of the variability in $P$ and $g_{\mathrm{s}}$ than leaf osmotic 349concentration.

350

351Although we aimed to maintain the same value of VPD in all experiments (see above), there was 352some variation; differences in VPD had a significant effect (Table 2 and 3) on leaf gas exchange, 353and this was accounted for in the statistical analysis.

\section{4}

355Non-stomatal limitations to photosynthesis

357Over the whole drought dataset, the photosynthetic efficiency $P / c_{\mathrm{i}}$ ranged from almost zero to 358slightly over $0.06 \mu \mathrm{mol} \mathrm{m} \mathrm{m}^{-2}$, apparent $V_{\text {cmax }}$ varied from 4 to $83 \mu \mathrm{mol} \mathrm{m}^{-2} \mathrm{~s}^{-1}$ and apparent $J_{\max }$ 359varied from 8 to $137 \mu \mathrm{mol} \mathrm{m} \mathrm{m}^{-2} \mathrm{~s}^{-1}$ (Fig. 4), decreasing with increasing leaf osmotic concentration 360(Fig $4 \mathrm{~A}, \mathrm{C}$ and $\mathrm{E}$ ) and decreasing leaf water potential (Fig. $4 \mathrm{~B}, \mathrm{D}$ and F). The $P / C_{\mathrm{i}}$ versus osmotic 361concentration and $P / C_{\mathrm{i}}$ versus leaf water potential relationships were highly significant when fitted 362with a power-law function (Table 2), the species-average exponents being -0.04 and -0.009 , 363respectively (Table S1). $V_{\text {cmax }}$ decreased significantly with increasing leaf osmotic concentration 364with a species-average power-law exponent of -1.91 (Table 2; Table S1), while the effect of leaf 365water potential on $V_{\text {cmax }}$ was not significant (Table 2). The $J_{\max }$ versus leaf osmotic concentration 366and $J_{\max }$ versus leaf water potential relationships had species-average exponents of -1.51 and -0.23 , 367respectively (Table 2; Table S1 for species specific results). For $P / c_{\mathrm{i}}$, apparent $V_{\text {cmax }}$ and apparent $368 J_{\max }$, the model with leaf osmotic concentration explained more of the variation than the model with 369leaf water potential (see model R2 in Table 2).

371In the notching experiment, $P / C_{\mathrm{i}}$ decreased with increasing leaf osmotic concentration and 372decreasing leaf water potential (Fig. 5), with species-average power-law exponents of -0.032 and - 
3730.010, respectively (Table 3, Table S2 for species specific results). There was no effect of leaf 374temperature on either of these relations but there was a significant difference between species for 375both of them.

\section{6}

377Non-stomatal vs. stomatal limitations to photosynthesis

378

$379 P / c_{\mathrm{i}}$ decreased simultaneously with decreasing $g_{\mathrm{s}}$ as the drought progressed (Fig. 6A). The relation 380was highly significant $(\mathrm{p}<0.001)$ and has a saturating shape indicating that the decrease in $P / c_{\mathrm{i}}$ was

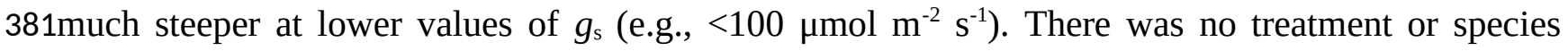
382effect. Similarly, during notching $P / c_{\mathrm{i}}$ decreased significantly with decreasing $g_{\mathrm{s}}$ (Fig. 6B) following 383a power-law relation with an average exponent of 0.015 (Table 3, table S2). The relation was not 384affected by changes in leaf temperature but was affected by the interaction between $g_{\mathrm{s}}$ and the 385species.

386

387In the notching experiment, changes in $P / c_{\mathrm{i}}$ were consistent with changes in measured assimilation 388at a given $C_{\mathrm{i}}$ versus assimilation predicted for that $C_{\mathrm{i}}$ value based on the $A$ - $C_{\mathrm{i}}$ curve (suppl. Mat. Note 389S1 and Fig. S1).

390

391Relation between stomatal conductance and hydraulic conductance

392

393In the drought experiment, a strong positive linear relationship $\left(\mathrm{p}<0.0001, \mathrm{R}^{2}=0.57\right.$ Fig. 7A) was 394found between measured values of $E$ and modelled $E$ values obtained (after normalization) from 395eqn (7). This finding supports the theoretical prediction of the optimization hypothesis, that 396stomatal conductance is proportional to the square root of the soil-to-leaf hydraulic conductance 397 from soil to leaf. There was no species difference in the observed relation.

398

399A similar relationship was found in the notching experiment $\left(\mathrm{p}<0.0001\right.$, marginal $\mathrm{R}^{2}=0.41$, 400conditional $\mathrm{R}^{2}=0.66$, Fig. 7B). There was a significant species effect on the slope of the relation 401( $\mathrm{p}=0.0006)$, with pine having a steeper slope than the broadleaves species

402

\section{Discussion}

404

405NSL increase with decreasing leaf water status and increasing leaf sugar/osmotic status 406(hypothesis 1) 
408We found significant quantitative relations between various measures of NSL (i.e. changes in $P / c_{\mathrm{i}}$, 409apparent $V_{\text {cmax }}$ and apparent $J_{\max }$ ) and changes in both leaf osmotic concentration and leaf water 410potential. The relations were significant despite the high level of noise in the measured variables of 411interest, especially in the drought experiment which involved sampling different individuals for 412each measurement.

413

414Previous studies have linked soil water status to changes in NSL (Drake et al., 2017) or some of its 415components, such as decreased mesophyll conductance (Noormets et al., 2001; Diaz-Espejo et al., 4162007) or biochemical limitation through temporary or permanent inactivation of Rubisco (Noormets 417et al., 2001; Salvucci \& Crafts-Brandner, 2004; Feller, 2016). The relative importance of mesophyll 418and biochemical limitation in NSL is subject to debate and may depend on species, type of stress 419and its duration (e.g., Cano et al., 2014; Gimeno et al., 2019), making modelling of NSL potentially 420challenging. While our results do not address these underlying mechanisms explicitly, they extend 421previous studies by establishing relationships between NSL and leaf (rather than soil) water status 422and leaf osmotic status (Box 1), thereby addressing in a simple way the need to represent NSL 423within plant models (e.g., Gimeno et al., 2019) to better predict plant responses to environmental 424change. In particular, these relationships support the basic assumptions of the optimization theory of 425Hölttä et al. (2017) and Dewar et al. (2018), in which NSL and stomatal control are coordinated to 426maximize leaf photosynthesis.

427

428We observed a strong relationship between NSL and leaf osmolyte concentration, particularly in the 429drought experiment in which leaf osmolyte concentration explained more of the variation in NSL 430than overall changes in leaf water potential. This result has important implications for the response 431of tree photosynthesis to drought stress. Osmotic potential has been repeatedly demonstrated to 432decrease during drought stress, in order to maintain the turgor of the mesophyll under decreased 433water potential (e.g., Sevanto et al., 2014; Salmon et al., 2015; Lintunen et al., 2016). Trees also 434regulate their leaf osmotic potential to cope with osmotic stress, for example in the case of in 435mangroves (Rada et al., 1989) or when growing on saline soil, or to avoid frost damage (Levitt \& 436Scarth, 1936; Charrier et al., 2018). Osmotically active solutes in leaves include soluble sugars, as 437well as ions and amino acids (e.g. proline) that can accumulate under stress (e.g., Talbott \& Zeiger, 4381996; Huang \& Jander, 2017). Soluble sugars likely represent a large share of the osmotically active 439compounds in the leaves of the tree species in our study (Morgan, 1984; Paljakka et al., 2017), but 440ions such as $\mathrm{Na}+$ and $\mathrm{K}+$ are also likely to constitute part of the measured osmolytes (in particular 
441due to the freezing treatment of the samples). Leaf sugar concentration has previously been 442associated with increasing NSL in some trees and herbaceous plants, both in C3 and C4 metabolism 443(e.g., Jeannette et al., 2000; Turnbull et al., 2002; Franck et al., 2006; Hüve et al., 2006; Quentin et 444al., 2013; Cano et al., 2014; Ramalho et al., 2014; Kitao et al., 2015). This sugar-mediated 445repression of photosynthesis is also consistent with earlier studies which showed that decreasing 446sink strength limits photosynthetic efficiency (Azcón-Bieto, 1983; Goldschmidt \& Huber, 1992; 447Nakano et al., 2000; Hölttä et al., 2017). Specifically, increasing sink strength has been associated 448with increasing mesophyll conductance in rice (Detmann et al., 2012). However, none of the 449previous studies have quantified this relationship across multiple species and conditions, thereby 450hampering its inclusion in models of plant photosynthetic response to stress.

451

452 These correlations are similar across timescale and species (hypothesis 2) 453

454Overall, our results support the growing body of evidence that NSL can take place over periods 455ranging from days to weeks (e.g., Drake et al., 2017), in particular in the case of plant physiological 456response to drought. However, the notching results clearly demonstrate that NSL also occurs within 457minutes, to changes in tree carbon and water status, on timescales comparable to stomatal 458responses. Such short-term responses of NSL are less-well documented than the long-term response 459(e.g., Gimeno et al., 2019), even though mesophyll conductance has been shown to be able to 460respond within minutes to changes in environmental conditions (see for example Flexas et al., 2012 461and references therein). The species-average power-law exponents describing the $P / c_{\mathrm{i}}$ vs. leaf 462osmotic concentration and $P / c_{\mathrm{i}}$ vs. leaf water potential relationships were broadly comparable on 463different timescales (-0.04 and -0.009 in the drought experiment, -0.032 and -0.01 in the notching 464experiment, respectively).

465

466Our results also show that despite a common pattern among all species for NSL responses to 467changes in leaf water and osmotic status, there was some species-specific differences. These results 468are in agreement with earlier studies showing that the amount of drought-induced NSL may vary 469according to the species resistance to drought (Ni \& Pallardy, 1992), their acclimation to drought 470conditions (Kubiske et al., 1996), or tree development stage. Furthermore, different species 471acclimated to different environments may respond differently to drought. For example, Galmés et 472al. (2007) showed that in drought-adapted Mediterranean species, drought mostly affected 473mesophyll conductance and had little effect on biochemical limitation. The observed decreases in 
474the apparent $V_{\text {cmax }}$ and $J_{\max }$ during our drought experiment are consistent with such biochemical 475limitations, which can be expected for boreal species not adapted to drought.

476

477 NSL and stomatal limitation to photosynthesis are coordinated on similar time scales and for 478different species (hypothesis 3)

479

480Although our results show that stomatal and non-stomatal limitations to photosynthesis occurred 481simultaneously, the former dominated during mild water stress while the latter dominated during 482severe water stress (Fig. 6 and Supplementary Materials Fig. S1). This result is in agreement with 483previous studies of NSL responses to drought (Kubiske et al., 1996; Maroco et al., 2002; Sagardoy 484et al., 2010). It has been found that NSL was present throughout an experimental drought imposed 485on four Australian species, but its importance increased with increasing drought stress (Drake et al., 4862017). Similar results were found for young ashes and oaks (Grassi \& Magnani, 2005). While the 487mechanisms of NSL might differ across species and time scales (e.g. the relative importance of 488changes in mesophyll conductance versus biochemical limitation), our results clearly show a very 489similar quantitative response of NSL to osmotic concentration and water potential at short- and 490long-term scales. The close coordination between NSL and stomatal limitations to photosynthesis 491supports the theoretical framework (Fig. 1) in which the photosynthesis rate in maximized by 492balancing between these two limitations to photosynthesis.

493

494The theoretical relationship between $g_{s}$ and $K_{s l}$ is supported by experimental data (hypothesis 4) 495

496The significant linear relation between modelled and measured $E$ found in both the drought and the 497notching experiments supports the theoretical prediction that $g_{\mathrm{s}}$ scales with the square root of $K_{\mathrm{sl}}$, 498based on the hypothesis that NSL and stomatal control are coordinated so as to maximize leaf 499photosynthetic rate (Hölttä et al., 2017; Dewar et al., 2018). Soil-to-leaf hydraulic conductance 500plays an important role in this hypothesis, because it determines how much water potential 501decreases (and osmotic concentration increases) for a given change in stomatal conductance. This 502prediction is consistent with a large number of experimental studies showing a tight correlation 503between plant hydraulic conductance and stomatal conductance (Sperry et al., 1993; Cochard et al., 5042002; Hernandez-Santana et al., 2016), as well as some earlier models coupling $\mathrm{g}_{\mathrm{s}}$ to changes in $\mathrm{K}_{\mathrm{sl}}$ 505(Williams et al., 1996; Sperry et al., 2017) In our theoretical framework, the coupling of $K_{s l}$ to $g_{s}$ 506occurs through NSL; for a small $K_{s l}$ (in comparison to large $K_{s l}$ ), a given transpiration rate induces a 
507larger decrease in NSL (Fig. 1), and the stomatal conductance that maximized photosynthesis is 508therefore lower.

509

510Conclusion

511

512We established quantitative relationships describing the dependence of non-stomatal limitations to 513photosynthesis on leaf osmotic concentration and leaf water potential on both short (minutes) and 514long (weeks) timescales. Stomatal conductance was found to vary with soil-to-leaf hydraulic 515conductance in a manner consistent with the predictions of the hypothesis that stomatal and non516stomatal limitations to photosynthesis are coordinated so as to maximize the instantaneous rate of 517leaf photosynthesis. These results provide a basis for including non-stomatal limitations to 518photosynthesis in models of tree responses to drought in a simple way that does not require a 519detailed representation of the underlying mechanisms.

520

521Acknowledgment

522

523This study was supported by by the Academy of Finland (project \#312571, \#282842, \#310375, 524\#307331, \#324014 and \#323843). We are especially thankful to David Granot for insightful 525discussions. We also thank Daniel Richterich for the maintenance of the greenhouse. We thank two 526anonymous reviewers for their constructive comments.

527

528Author contribution

529YS, TV and TH planned and designed the experiment. YS, AL, AD and TC performed the 530experiments. YS analyzed the data with the help of AL and AD. YS wrote the manuscript with the 531help of all co-author and particularly TH and RD.

532 


\section{References}

534Azcón-Bieto J. 1983. Inhibition of photosynthesis by carbohydrates in wheat leaves. Plant Physiology 73(3): $535 \quad$ 681-686.

536Ball JT, Woodrow IE, Berry JA 1987. A model predicting stomatal conductance and its contribution to the 537 control of photosynthesis under different environmental conditions. In: Biggins J ed. Progress in 538 Photosynthesis Research: Volume 4 Proceedings of the VIlth International Congress on 539 Photosynthesis Providence, Rhode Island, USA, August 10-15, 1986. Dordrecht: Springer $540 \quad$ Netherlands, 221-224.

541Buckley TN, Diaz-Espejo A. 2015. Partitioning changes in photosynthetic rate into contributions from 542 different variables. Plant, Cell \& Environment 38(6): 1200-1211.

543Callister AN, Arndt SK, Adams MA. 2006. Comparison of four methods for measuring osmotic potential of $544 \quad$ tree leaves. Physiologia Plantarum 127(3): 383-392.

545Cano FJ, López R, Warren CR. 2014. Implications of the mesophyll conductance to $\mathrm{CO}_{2}$ for photosynthesis 546 and water-use efficiency during long-term water stress and recovery in two contrasting Eucalyptus $547 \quad$ species. $37(11): 2470-2490$.

548Charrier G, Lacointe A, Améglio T. 2018. Dynamic modeling of carbon metabolism during the dormant 549 period accurately predicts the changes in frost hardiness in walnut trees Juglans regia L. 9(1746).

550Choat B, Jansen S, Brodribb TJ, Cochard H, Delzon S, Bhaskar R, Bucci SJ, Feild TS, Gleason SM, Hacke UG, 551 et al. 2012. Global convergence in the vulnerability of forests to drought. Nature 491: 752-756.

552Cochard H, Coll L, Le Roux X, Améglio T. 2002. Unraveling the effects of plant hydraulics on stomatal $553 \quad$ closure during water stress in walnut. Plant Physiology 128(1): 282-290.

554Cowan I, Farquhar G 1977. Stomatal function in relation to leaf metabolism and environment. Symposia of 555 the Society for Experimental Biology. 471.

556Detmann KC, Araújo WL, Martins SCV, Sanglard LMVP, Reis JV, Detmann E, Rodrigues FÁ, Nunes-Nesi A, 557 Fernie AR, DaMatta FM. 2012. Silicon nutrition increases grain yield, which, in turn, exerts a feed-

558 forward stimulation of photosynthetic rates via enhanced mesophyll conductance and alters 559 primary metabolism in rice. New Phytologist 196(3): 752-762.

560Dewar R, Mauranen A, Mäkelä A, Hölttä T, Medlyn B, Vesala T. 2018. New insights into the covariation of 561 stomatal, mesophyll and hydraulic conductances from optimization models incorporating 562 nonstomatal limitations to photosynthesis. New Phytologist 217(2): 571-585.

563Diaz-Espejo A, Nicolás E, Fernández JE. 2007. Seasonal evolution of diffusional limitations and 564 photosynthetic capacity in olive under drought. Plant, Cell \& Environment 30(8): 922-933.

565Drake JE, Power SA, Duursma RA, Medlyn BE, Aspinwall MJ, Choat B, Creek D, Eamus D, Maier C, Pfautsch 566 S, et al. 2017. Stomatal and non-stomatal limitations of photosynthesis for four tree species under 567 drought: A comparison of model formulations. Agricultural and Forest Meteorology 247: 454-466.

568Duursma RA. 2015. Plantecophys - an R package for analysing and modelling leaf gas exchange data. PLOS 569 ONE 10(11): e0143346.

570Feller U. 2016. Drought stress and carbon assimilation in a warming climate: Reversible and irreversible $571 \quad$ impacts. Journal of Plant Physiology 203: 84-94.

572Flexas J, Barbour MM, Brendel O, Cabrera HM, Carriquí M, Díaz-Espejo A, Douthe C, Dreyer E, Ferrio JP, 573 Gago J, et al. 2012. Mesophyll diffusion conductance to $\mathrm{CO}_{2}$ : An unappreciated central player in $574 \quad$ photosynthesis. Plant Science 193-194: 70-84.

575Flexas J, Ribas-Carbó M, Diaz-Espejo A, Galmés J, Medrano H. 2008. Mesophyll conductance to $\mathrm{CO}_{2}$ : $576 \quad$ current knowledge and future prospects. Plant, Cell \& Environment 31(5): 602-621.

577Franck N, Vaast P, Genard M, Dauzat J. 2006. Soluble sugars mediate sink feedback down-regulation of leaf 578 photosynthesis in field-grown Coffea arabica. Tree Physiology 26(4): 517-525.

579Gago J, Daloso DdM, Figueroa CM, Flexas J, Fernie AR, Nikoloski Z. 2016. Relationships of leaf net 580 photosynthesis, stomatal conductance, and mesophyll conductance to primary metabolism: A 581 multispecies meta-analysis approach. Plant Physiology 171(1): 265-279.

582Galmés J, Medrano H, Flexas J. 2007. Photosynthetic limitations in response to water stress and recovery in 583 Mediterranean plants with different growth forms. New Phytologist 175(1): 81-93. 
584Gimeno TE, Saavedra N, Ogée J, Medlyn BE, Wingate L. 2019. A novel optimization approach incorporating 585 non-stomatal limitations predicts stomatal behaviour in species from six plant functional types. 586 Journal of Experimental Botany 70(5): 1639-1651.

587Goldschmidt EE, Huber SC. 1992. Regulation of photosynthesis by end-product accumulation in leaves of $588 \quad$ plants storing starch, sucrose, and hexose sugars. Plant Physiology 99(4): 1443-1448.

589Granot D, David-Schwartz R, Kelly G. 2013. Hexose kinases and their role in sugar-sensing and plant $590 \quad$ development. Frontiers in Plant Science 4(44).

591Grassi G, Magnani F. 2005. Stomatal, mesophyll conductance and biochemical limitations to 592 photosynthesis as affected by drought and leaf ontogeny in ash and oak trees. Plant, Cell \& $593 \quad$ Environment 28(7): 834-849.

594Hernandez-Santana V, Rodriguez-Dominguez CM, Fernández JE, Diaz-Espejo A. 2016. Role of leaf hydraulic 595 conductance in the regulation of stomatal conductance in almond and olive in response to water 596 stress. Tree Physiology 36(6): 725-735.

597Hölttä T, Lintunen A, Chan T, Mäkelä A, Nikinmaa E. 2017. A steady-state stomatal model of balanced leaf 598 gas exchange, hydraulics and maximal source-sink flux. Tree Physiology 37(7): 851-868.

599Huang C-W, Domec J-C, Palmroth S, Pockman WT, Litvak ME, Katul GG. 2018. Transport in a coordinated 600 soil-root-xylem-phloem leaf system. Advances in Water Resources 119: 1-16.

601Huang T, Jander G. 2017. Abscisic acid-regulated protein degradation causes osmotic stress-induced 602 accumulation of branched-chain amino acids in Arabidopsis thaliana. Planta 246(4): 737-747.

603Hüve K, Bichele I, Tobias M, Niinemets Ü. 2006. Heat sensitivity of photosynthetic electron transport varies 604 during the day due to changes in sugars and osmotic potential. Plant, Cell \& Environment 29(2): $605 \quad 212-228$.

606Jarvis PG, Monteith JL, Weatherley PE. 1976. The interpretation of the variations in leaf water potential 607 and stomatal conductance found in canopies in the field. Philosophical Transactions of the Royal 608 Society of London. B, Biological Sciences 273(927): 593-610.

609Jeannette E, Reyss A, Grégory N, Gantet P, Prioul J-L. 2000. Carbohydrate metabolism in a heat-girdled 610 maize source leaf. Plant, Cell \& Environment 23(1): 61-69.

611Kaiser E, Morales A, Harbinson J, Kromdijk J, Heuvelink E, Marcelis LFM. 2015. Dynamic photosynthesis in 612 different environmental conditions. Journal of Experimental Botany 66(9): 2415-2426.

613Kelly G, Moshelion M, David-Schwartz R, Halperin O, Wallach R, Attia Z, Belausov E, Granot D. 2013. $614 \quad H$ Hexokinase mediates stomatal closure. The Plant Journal 75(6): 977-988.

615Kelly G, Sade N, Attia Z, Secchi F, Zwieniecki M, Holbrook NM, Levi A, Alchanatis V, Moshelion M, Granot 616 D. 2014. Relationship between hexokinase and the aquaporin PIP1 in the regulation of 617 photosynthesis and plant growth. PLOS ONE 9(2): e87888.

618Kelly G, Sade N, Doron-Faigenboim A, Lerner S, Shatil-Cohen A, Yeselson Y, Egbaria A, Kottapalli J, 619 Schaffer AA, Moshelion M. 2017. Sugar and hexokinase suppress expression of PIP aquaporins and 620 reduce leaf hydraulics that preserves leaf water potential. The Plant Journal 91(2): 325-339.

621Kikuta SB, Richter H. 1992. Leaf discs or press saps? A comparison of techniques for the determination of 622 osmotic potentials in freeze-thawed leaf material. Journal of Experimental Botany 43(8): 10396231044.

624Kitao M, Yazaki K, Kitaoka S, Fukatsu E, Tobita H, Komatsu M, Maruyama Y, Koike T. 2015. Mesophyll 625 conductance in leaves of Japanese white birch (Betula platyphylla var. japonica) seedlings grown 626 under elevated $\mathrm{CO}_{2}$ concentration and low $\mathrm{N}$ availability. Physiologia Plantarum 155(4): 435-445.

627Klein T, Hartmann H. 2018. Climate change drives tree mortality. Science 362(6416): 758-758.

628Kubiske M, Abrams M, Mostoller S. 1996. Stomatal and nonstomatal limitations of photosynthesis in 629 relation to the drought and shade tolerance of tree species in open and understory environments. 630 Trees 11: 76-82.

631Leuning R. 1995. A critical appraisal of a combined stomatal-photosynthesis model for C3 plants. 18(4): $632 \quad 339-355$.

633Levitt J, Scarth GW. 1936. Frost-hardening studies with living cells: I. Osmotic and bound water changes in 634 relation to frost resistance and the seasonal cycle. Canadian Journal of Research 14c(7): 267-284. 
635Lintunen A, Paljakka T, Jyske T, Peltoniemi M, Sterck F, von Arx G, Cochard H, Copini P, Caldeira MC, 636 Delzon S, et al. 2016. Osmolality and non-structural carbohydrate composition in the secondary 637 phloem of trees across a latitudinal gradient in Europe. Frontiers in Plant Science 7(726).

638Long SP, Ainsworth EA, Rogers A, Ort DR. 2004. Rising atmospheric carbon dioxide: plants FACE the future. $639 \quad$ Annu. Rev. Plant Biol. 55: 591-628.

640Maroco JP, Rodrigues ML, Lopes C, Chaves MM. 2002. Limitations to leaf photosynthesis in field-grown 641 grapevine under drought-metabolic and modelling approaches. Functional Plant Biology 29(4): 451642459.

643McDowell NG, Beerling DJ, Breshears DD, Fisher RA, Raffa KF, Stitt M. 2011. The interdependence of 644 mechanisms underlying climate-driven vegetation mortality. Trends in Ecology and Evolution 645 26(10): 523-532.

646Medlyn BE, Duursma RA, Eamus D, Ellsworth DS, Prentice IC, Barton CVM, Crous KY, De Angelis P, 647 Freeman M, Wingate L. 2011. Reconciling the optimal and empirical approaches to modelling 648 stomatal conductance. Global Change Biology 17(6): 2134-2144.

649Mitchell PJ, McAdam SAM, Pinkard EA, Brodribb TJ. 2017. Significant contribution from foliage-derived $650 \quad A B A$ in regulating gas exchange in Pinus radiata. Tree Physiology 37(2): 236-245.

651Morgan JM. 1984. Osmoregulation and water stress in higher plants. Annual review of plant physiology $652 \quad 35(1): 299-319$.

653Nakano H, Muramatsu S, Makino A, Mae T. 2000. Relationship between the suppression of photosynthesis 654 and starch accumulation in the pod-removed bean. Functional Plant Biology 27(2): 167-173.

655Nardini A, Salleo S. 2000. Limitation of stomatal conductance by hydraulic traits: sensing or preventing $656 \quad x y l e m$ cavitation? Trees 15(1): 14-24.

657Ni B-R, Pallardy SG. 1992. Stomatal and nonstomatal limitations to net photosynthesis in seedlings of $658 \quad$ woody angiosperms. Plant Physiology 99(4): 1502-1508.

659Nikinmaa E, Hölttä T, Hari P, Kolari P, Mäkelä A, Sevanto S, Vesala T. 2013. Assimilate transport in phloem 660 sets conditions for leaf gas exchange. Plant, Cell \& Environment 36(3): 655-669.

661Noormets A, Sôber A, Pell EJ, Dickson RE, Podila GK, Sôber J, Isebrands JG, Karnosky DF. 2001. Stomatal 662 and non-stomatal limitation to photosynthesis in two trembling aspen (Populus tremuloides Michx.) 663 clones exposed to elevated $\mathrm{CO}_{2}$ and/or $\mathrm{O}_{3}$. Plant, Cell \& Environment 24(3): 327-336.

664Paljakka T, Jyske T, Lintunen A, Aaltonen H, Nikinmaa E, Hölttä T. 2017. Gradients and dynamics of inner 665 bark and needle osmotic potentials in Scots pine (Pinus sylvestris L.) and Norway spruce (Picea 666 abies L. Karst). Plant, Cell \& Environment 40(10): 2160-2173.

667Pinheiro J, Bates D, DebRoy S, Sarkar D, R Core Team. 2017. nlme: Linear and Nonlinear Mixed Effects $668 \quad$ Models_. R package version 3.1-131.

669Quentin AG, Close DC, Hennen LMHP, Pinkard EA. 2013. Down-regulation of photosynthesis following 670 girdling, but contrasting effects on fruit set and retention, in two sweet cherry cultivars. Plant $671 \quad$ Physiology and Biochemistry 73: 359-367.

672R Core Team. 2017. R: A language and environment for statistical computing. .

673Rada F, Goldstein G, Orozco A, Montilla M, Zabala O, Azocar A. 1989. Osmotic and turgor relations of 674 three mangrove ecosystem species Functional Plant Biology 16(6): 477-486.

675Ramalho JC, Zlatev ZS, Leitão AE, Pais IP, Fortunato AS, Lidon FC. 2014. Moderate water stress causes 676 different stomatal and non-stomatal changes in the photosynthetic functioning of Phaseolus 677 vulgaris L. genotypes. Plant Biology 16(1): 133-146.

678Sagardoy R, Vázquez S, Florez-Sarasa ID, Albacete A, Ribas-Carbó M, Flexas J, Abadía J, Morales F. 2010. 679 Stomatal and mesophyll conductances to $\mathrm{CO}_{2}$ are the main limitations to photosynthesis in sugar 680 beet (Beta vulgaris) plants grown with excess zinc. New Phytologist 187(1): 145-158.

681Salmon Y, Torres-Ruiz JM, Poyatos R, Martinez-Vilalta J, Meir P, Cochard H, Mencuccini M. 2015. 682 Balancing the risks of hydraulic failure and carbon starvation: a twig scale analysis in declining Scots 683 pine. Plant, Cell \& Environment 38: 2575-2588.

684Salvucci ME, Crafts-Brandner SJ. 2004. Inhibition of photosynthesis by heat stress: the activation state of 685 Rubisco as a limiting factor in photosynthesis. Physiologia Plantarum 120(2): 179-186. 
686Schneider CA, Rasband WS, Eliceiri KW. 2012. NIH Image to ImageJ: 25 years of image analysis. Nature $687 \quad$ Methods 9: 671.

688Sevanto S, McDowell NG, Dickman LT, Pangle R, Pockman WT. 2014. How do trees die? A test of the 689 hydraulic failure and carbon starvation hypotheses. Plant, Cell \& Environment 37(1): 153-161.

690Sperry JS, Alder NN, Eastlack SE. 1993. The effect of reduced hydraulic conductance on stomatal 691 conductance and xylem cavitation. Journal of Experimental Botany 44(6): 1075-1082.

692Sperry JS, Venturas MD, Anderegg WRL, Mencuccini M, Mackay DS, Wang Y, Love DM. 2017. Predicting 693 stomatal responses to the environment from the optimization of photosynthetic gain and hydraulic $694 \quad$ cost. 40(6): 816-830.

695Stitt M, Krapp A. 1999. The interaction between elevated carbon dioxide and nitrogen nutrition: the 696 physiological and molecular background. Plant, Cell \& Environment 22(6): 583-621.

697Talbott LD, Zeiger E. 1996. Central roles for potassium and sucrose in guard-cell osmoregulation. 111(4): $698 \quad$ 1051-1057.

699Turgeon R. 2010. The role of phloem loading reconsidered. 152(4): 1817-1823.

700Turnbull MH, Murthy R, Griffin KL. 2002. The relative impacts of daytime and night-time warming on 701 photosynthetic capacity in Populus deltoides. Plant, Cell \& Environment 25(12): 1729-1737.

702Warren CR, Bleby T, Adams MA. 2007. Changes in gas exchange versus leaf solutes as a means to cope 703 with summer drought in Eucalyptus marginata. Oecologia 154(1): 1.

704Williams M, Rastetter EB, Fernandes DN, Goulden ML, Wofsy SC, Shaver GR, Melillo JM, Munger JW, Fan

705 S-M, Nadelhoffer KJ. 1996. Modelling the soil-plant-atmosphere continuum in a Quercus-Acer

706 stand at Harvard Forest: the regulation of stomatal conductance by light, nitrogen and soil/plant $707 \quad$ hydraulic properties. 19(8): 911-927.

708Wong SC, Cowan IR, Farquhar GD. 1979. Stomatal conductance correlates with photosynthetic capacity. $709 \quad$ Nature 282(5737): 424-426.

710Zuur A, leno E, Walker N, Saveliev A, Smith G. 2009. Mixed effects models and extensions in ecology with 711 R. Gail M, Krickeberg K, Samet JM, Tsiatis A, Wong W, editors. New York, NY: Spring Science and 712 Business Media.

713

714 
715Box 1: While our experimental design does not allow testing for the physiological mechanisms 71kunderlying the relation between stomatal and non-stomatal limitation to photosynthesis with 717changes in osmotic concentration and water status, they show a coordination of stomatal and non$718 s t o m a t a l$ response to changes in leaf water and osmotic status that is in agreement with a proposition 719that a joint molecular pathway aiming at limiting unnecessary water loss by leaves would respond 72 pto both water stress and sugar accumulation in leaves (Kelly et al., 2017). Hexokinase has been 721observed in Arabidopsis and tomato (e.g., Granot et al., 2013; Kelly et al., 2013; Kelly et al., 2014; 722Kelly et al., 2017) to play such a central role in regulating leaf physiological processes in response 723 to changes in sugar metabolism. Under the well-supported assumption that changes in leaf 724osmolality reflects changes in sugar concentration (Warren et al., 2007; Paljakka et al., 2017, but 725see above for more details) and that hexokinase would play a similar role in trees than in the 72 ppreviously studied plants, hexokinase would be a good candidate for the coordination mechanism 727underlying the simultaneous changes in stomatal and non-stomatal limitation in our study (see Fig. 7288). Briefly: increasing sugar concentration (for example as a result of decreased water content, 72pimpaired phloem transport or osmotic regulation) would stimulate the hexokinase activity. 730Increased hexokinase activity would decrease mesophyll conductance (Kelly et al., 2014) and could 731 be the sensing mechanisms triggering the downregulation of the photosynthetic machinery with 732increasing sugar concentration reported before (Stitt \& Krapp, 1999; Long et al., 2004). 733Furthermore, ABA production has been shown to increase with hexokinase signaling caused by 734increasing sugar concentration (Granot et al., 2013; Kelly et al., 2013) thus causing stomatal closure 735(e.g., Mitchell et al., 2017). 
737Table 1: Average ( \pm 1 S.E.) initial height and basal diameter of the four species of saplings used in 738the drought experiment.

\begin{tabular}{lcc}
\hline Species & Initial height $(\mathrm{cm})$ & Initial basal diameter $(\mathrm{cm})$ \\
\hline Pine & $75 \pm 8$ & $1.38 \pm 0.17$ \\
Spruce & $57 \pm 4$ & $0.83 \pm 0.15$ \\
Aspen & $98 \pm 11$ & $0.73 \pm 0.09$ \\
Birch & $58 \pm 12$ & $0.55 \pm 0.06$ \\
\hline
\end{tabular}


740Table 2: Result of the statistical test for the relations between $P / c_{\mathrm{i}}, V_{\mathrm{cmax}}, J_{\max }, P$ and $g_{\mathrm{s}}$ against leaf osmotic concentration and leaf water potential 741for saplings of four boreal species in the drought experiment. The response variables y $\left(P / c_{\mathrm{i}}, V_{\mathrm{cmax}}\right.$ and $\left.J_{\max }\right)$ were transformed to Y to meet the 742linear regression requirements. Similarly, the independent variables were transformed into $\mathrm{X}$ if needed. An environmental covariate (z) was 743added to account for possible differences in the measurement conditions. The model tested is $\mathrm{Y} \sim \mathrm{z}+\mathrm{X} *$ Species*Treatment (see text for more 744details). The $\mathrm{R}^{2}$ for the full model is given. Note that $\log (\mathrm{y}+1)$ was used when $\mathrm{y}$ was lower than 1 to avoid creating negative values.

\begin{tabular}{|c|c|c|c|c|c|c|c|c|c|c|}
\hline Response variable (y) & $P / C_{\mathrm{i}}$ & & $V_{\text {cmax }}$ & & $J_{\max }$ & & $P$ & & $g_{\mathrm{s}}$ & \\
\hline Transformation (Y) & $\log (y+1)$ & $\log (y+1)$ & $\log (y)$ & $\log (y)$ & $\log (y)$ & $\log (y)$ & $\log (\mathrm{y})$ & $\log (y)$ & $\mathrm{y}$ & $\log (y)$ \\
\hline Independent variable (x) & $\begin{array}{c}\text { osmotic } \\
\text { concentration }\end{array}$ & water potential & $\begin{array}{c}\text { osmotic } \\
\text { concentration }\end{array}$ & water potential & $\begin{array}{c}\text { osmotic } \\
\text { concentration }\end{array}$ & water potential & $\begin{array}{c}\text { osmotic } \\
\text { concentration }\end{array}$ & water potential & $\begin{array}{c}\text { osmotic } \\
\text { concentration }\end{array}$ & water potential \\
\hline Transformation (X) & $\log (\mathrm{x})$ & $\log (-x)$ & $\log (\mathrm{x})$ & $\log (-x)$ & $\log (\mathrm{x})$ & $\log (-x)$ & $\log (x)$ & $\log (-x)$ & $\log (x)$ & $\log (-x)$ \\
\hline $\mathrm{p}$-value for $\mathrm{X}$ & $210^{-9}$ & 0.0011 & $410^{-6}$ & ns & $310^{-7}$ & 0.039 & $210^{-16}$ & $810^{-13}$ & $710^{-8}$ & $810^{-8}$ \\
\hline \multicolumn{11}{|l|}{ Other variables p-values } \\
\hline VPD & 0.0003 & 0.001 & $310^{-9}$ & ns & ns & ns & ns & $110^{-5}$ & 0.017 & 0.003 \\
\hline species & $310^{-7}$ & $210^{-5}$ & $310^{-8}$ & $210^{-5}$ & $610^{-10}$ & $110^{-17}$ & $210^{-9}$ & $910^{-11}$ & $510^{-8}$ & $410^{-10}$ \\
\hline Treatment & ns & ns & ns & 0.082 & 0.038 & 0.013 & $510^{-5}$ & 0.001 & $810^{-7}$ & $510^{-6}$ \\
\hline $\mathrm{X}:$ Species & 0.0003 & ns. & ns & 0.072 & ns & 0.072 & 0.0048 & ns & 0.075 & ns \\
\hline $\mathrm{X}:$ Treatment & ns & 0.0013 & 0.036 & ns & 0.061 & 0.056 & ns & $310^{-7}$ & ns & 0.001 \\
\hline Species:Treatment & ns & ns & ns & ns & ns & ns & 0.0212 & 0.009 & 0.032 & 0.018 \\
\hline $\mathrm{X}$ :Species:Treatment & 0.04 & ns. & 0.006 & 0.0033 & 0.0045 & 0.013 & 0.0237 & ns & ns & ns \\
\hline Model $\mathrm{R}^{2}$ & 0.66 & 0.42 & 0.74 & 0.58 & 0.78 & 0.65 & 0.76 & 0.71 & 0.68 & 0.67 \\
\hline
\end{tabular}

745n.s.: non significant. Excl. excluded from the final model. 
746Table 3: Result of the statistical test for the relations between $P / c_{i}, P$ and $g_{s}$ against leaf osmotic 747concentration and leaf water potential for saplings of four boreal species in the notching 748experiment. The response variables y $\left(P / c_{i}\right)$ were transformed to $\mathrm{Y}$ to meet the linear regression 749requirements. Similarly, the independent variables were transformed into $\mathrm{X}$ if needed. An 750environmental covariate ( $\mathrm{z}$ ) was added to account for possible differences in the measurement 751conditions. The original model tested is $\mathrm{Y} \sim \mathrm{z}+\mathrm{X}^{*}$ Species and simplified when possible (see text for 752more details), the experimental run was added as a random term. The marginal $\mathrm{R}^{2}$ and the 753conditional $\mathrm{R}^{2}$ for the selected model are given. Note that $\log (\mathrm{y}+1)$ was used when $\mathrm{y}$ was lower than 7541 to avoid creating negative values.

\begin{tabular}{|c|c|c|c|c|c|c|c|}
\hline \multirow{2}{*}{$\begin{array}{l}\text { Response variable (y) } \\
\text { Transformation (Y) }\end{array}$} & \multicolumn{3}{|l|}{$P / c_{i}$} & \multicolumn{2}{|l|}{$P$} & \multicolumn{2}{|l|}{$g_{s}$} \\
\hline & $\log (y+1)$ & $\log (y+1)$ & $\log (y+1)$ & $\log (y)$ & $\log (y)$ & $\log (\mathrm{y})$ & $\log (y)$ \\
\hline Ind ongd & osmotic & water & & osmotic & water & osmotic & water \\
\hline illuepentuent valiadie $(x)$ & concentration & potential & $\mathrm{gs}_{\mathrm{s}}$ & concentration & potential & concentration & potential \\
\hline Transformation (X) & $\log (\mathrm{x})$ & $\log (-x)$ & $\log (x)$ & $\log (\mathrm{x})$ & $\log (-x)$ & $\log (\mathrm{x})$ & $\log (-x)$ \\
\hline p-value fpr X & $<0.0001$ & $<0.0001$ & $<0.0001$ & $<0.0001$ & $<0.0001$ & $<0.0001$ & $<0.0001$ \\
\hline environment (z) & Tleaf & Tleaf & Tleaf & VPD & VPD & VPD & VPD \\
\hline p-values for $\mathrm{z}$ & ns & $\mathrm{ns}$ & ns & 0.019 & 0.013 & 0.0095 & 0.0015 \\
\hline $\mathrm{p}$ values for species & 0.009 & 0.015 & 0.065 & ns & ns & 0.032 & ns \\
\hline $\mathrm{p}$ values for X:Specie & excl. & excl. & 0.004 & excl. & excl. & excl. & ns \\
\hline Marginal $\mathrm{R}^{2}$ & 0.31 & 0.38 & 0.75 & 0.30 & 0.43 & 0.26 & 0.49 \\
\hline Conditional $\mathrm{R}^{2}$ & 0.38 & 0.67 & 0.92 & 0.43 & 0.81 & 0.54 & 0.79 \\
\hline
\end{tabular}

755n.s.: non significant. Excl. excluded from the final model. 
756Figure 1: A schematic figure of net photosynthetic rate $(A)$ as a function of leaf internal $\mathrm{CO}_{2}$ 757concentration $\left(c_{i}\right)$ and leaf water and osmotic status. Stomatal opening causes $\mathrm{CO}_{2}$ supply to and $c_{i}$ 758to increase, but at the same time water potential is decreased and osmotic concentration is increased 759causing $A$ for a given $c_{i}$ to be lowered. The maximum photosynthesis rate is achieved at an 760intermediate, “optimal” stomatal conductance (see insert) to balance between the stomatal and non761stomatal limitations to photosynthesis. The "optimal” stomatal conductance is dependent on e.g. 762photosynthetic parameters, PAR, ambient $\mathrm{CO}_{2}\left(c_{a}\right)$, VPD, hydraulic conductance $\left(K_{s l}\right)$, and 763vulnerability to cavitation $\left(P L C_{50}\right)$.

764Figure 2: Gross photosynthetic rate $(P)$ and stomatal conductance $\left(\mathrm{g}_{\mathrm{s}}\right)$ as a function of leaf osmotic 765concentration and water potential for four species exposed to increasing drought stress. Well-water 766(circle) and drought-stressed (triangle) saplings are used in the same regression per species to cover 767a wide range of leaf osmolality and water potential, but more details about the statistical model can 768be found in Tables 2 and S1.

769Figure 3: Gross photosynthetic rate $(P)$ and transpiration $(E)$ as a function of leaf osmotic 770concentration and water potential for three species exposed to notching. Curves are fitted with 771power regression over the several replicates for each species (more details can be found in tables 3 772and S2).

773Figure 4: $P / c_{i}(\mathrm{~A}$ and $\mathrm{B}), V_{c \max }(\mathrm{C}$ and $\mathrm{D})$ and $J_{\max }(\mathrm{E}$ and $\mathrm{F})$ response to changes in leaf osmotic 774concentration (A, C and E) and water potential (B, D and F) as drought increases for saplings of 775 four common boreal species. Well-water (circle) and drought-stressed (triangle) saplings are used in 776the same regression per species to cover a wide range of leaf osmotic concentration and water 777potential, but more details about the statistical model can be found in Table 2 and Table S1. Note 778the different scales of the X-axis in panels A and B compared to the others, this is the results of 779unreliable $A-c_{i}$ curve measurements on very stress plants.

780Figure 5: $P / C_{i}$ response to leaf osmotic concentration (A) and water potential (B) of three species to 781notching. Curves are fitted with a power regression, more details can be found in tables 3 and S2.

782Figure 6: relation between non-stomatal limitation to photosynthesis estimated by changes in $P / c_{i}$ 783in response to changes in stomatal conductance, for saplings of four common boreal species 784exposed to drought (A) and for saplings of three common boreal species exposed to notching (B). 785For the drought, well-water (circle) and drought-stressed (triangle) saplings are used in the same 786regression per species to cover a wide range of leaf osmolality and water potential. For the 
787notching, curves are fitted with power relation between $g_{s}$ and $P / C_{i}$ and over the several replicates 788for each species. (See table 3 for the full statistical test).

789Figure 7: relation between $r / r_{\max }$ (see material and methods) and measured $E$ in the two 790experiements presented in this study: (A) saplings of four common boreal species exposed to 791drought. The relation tested between modelled $r / r_{\max }$ and $E$ was highly significant $(\mathrm{y}=0.27 \mathrm{x}$, $792 \mathrm{p}<0.0001, \mathrm{R}^{2}=0.54$ ). There was no difference between species. (B) saplings of three common boreal 793species exposed to notching. The relation tested between relative $r / r_{\max }$ and $E$ was highly significant 794( $<<0.0001$, marginal $\mathrm{R}^{2}=0.47$, conditional $\left.\mathrm{R}^{2}=0.79\right)$. Aspen and birch were not statistically different 795(y 0.113x for aspen and $\mathrm{y} \sim 0.086 \mathrm{x}$ for birch). Pine was significantly different from the other species 796(y 0.280x). $(\mathrm{p}<0.001)$.

797Figure 8: A conceptual model demonstrating the mechanisms by which sugar concentration can be 798linked to changes in stomatal and non-stomatal limitation to photosynthesis. Full arrows represent 799processes for which the causal link is established beyond doubt, while dashed arrows represents 800established processes but not as widely demonstrated as the previous one. Dark grey color 801represents environmental drivers and light grey physiological processes and variables. 


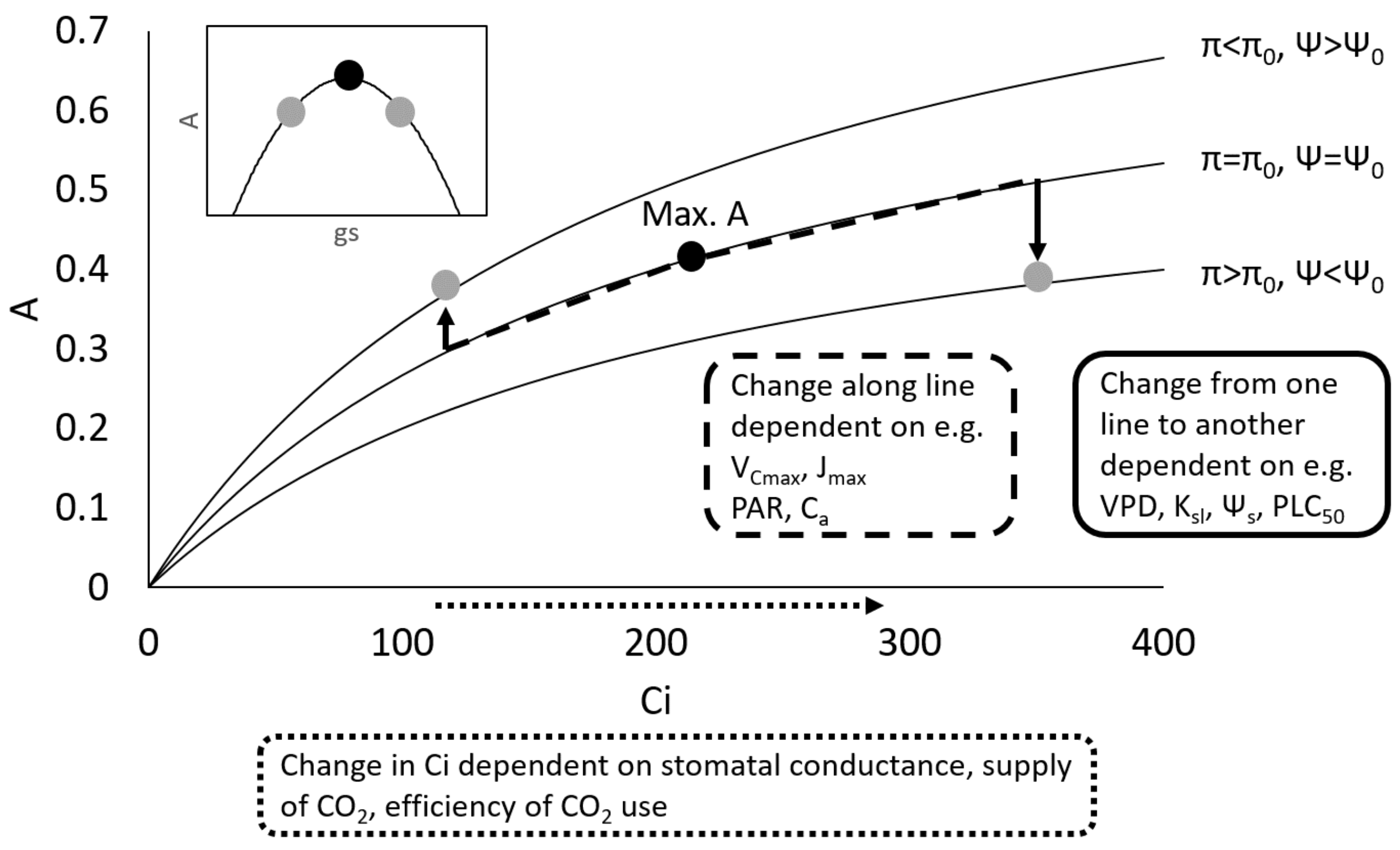




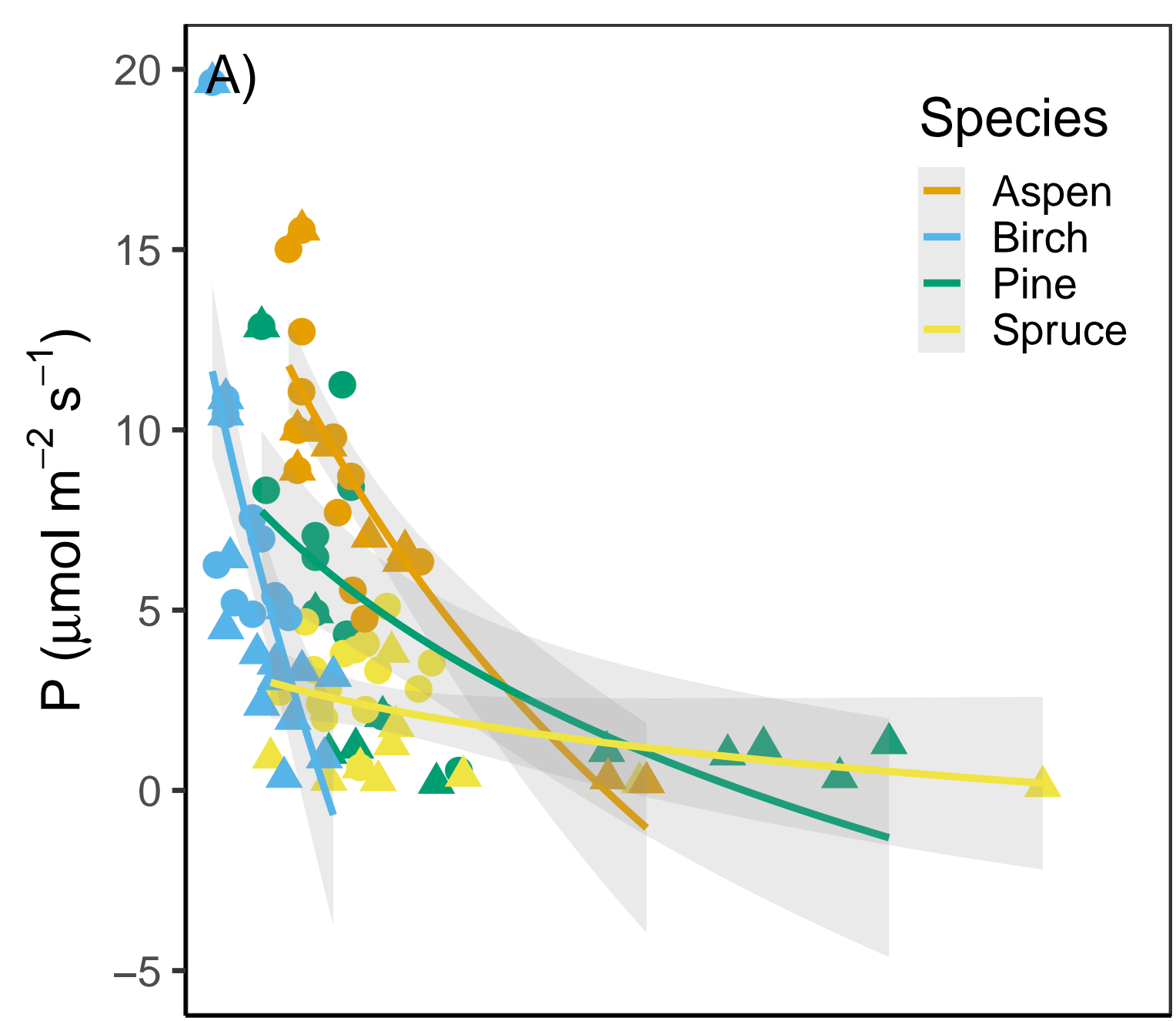

B)
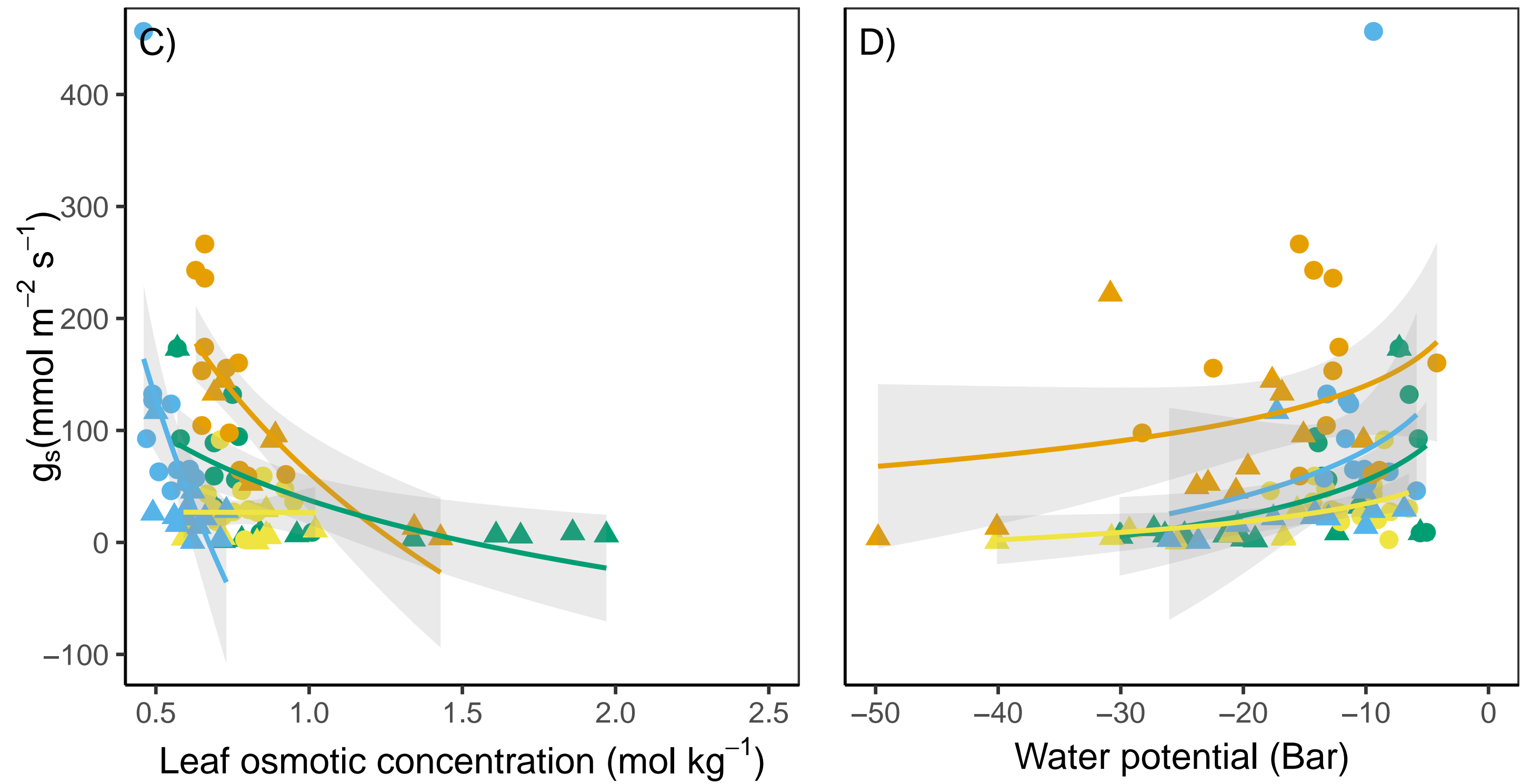


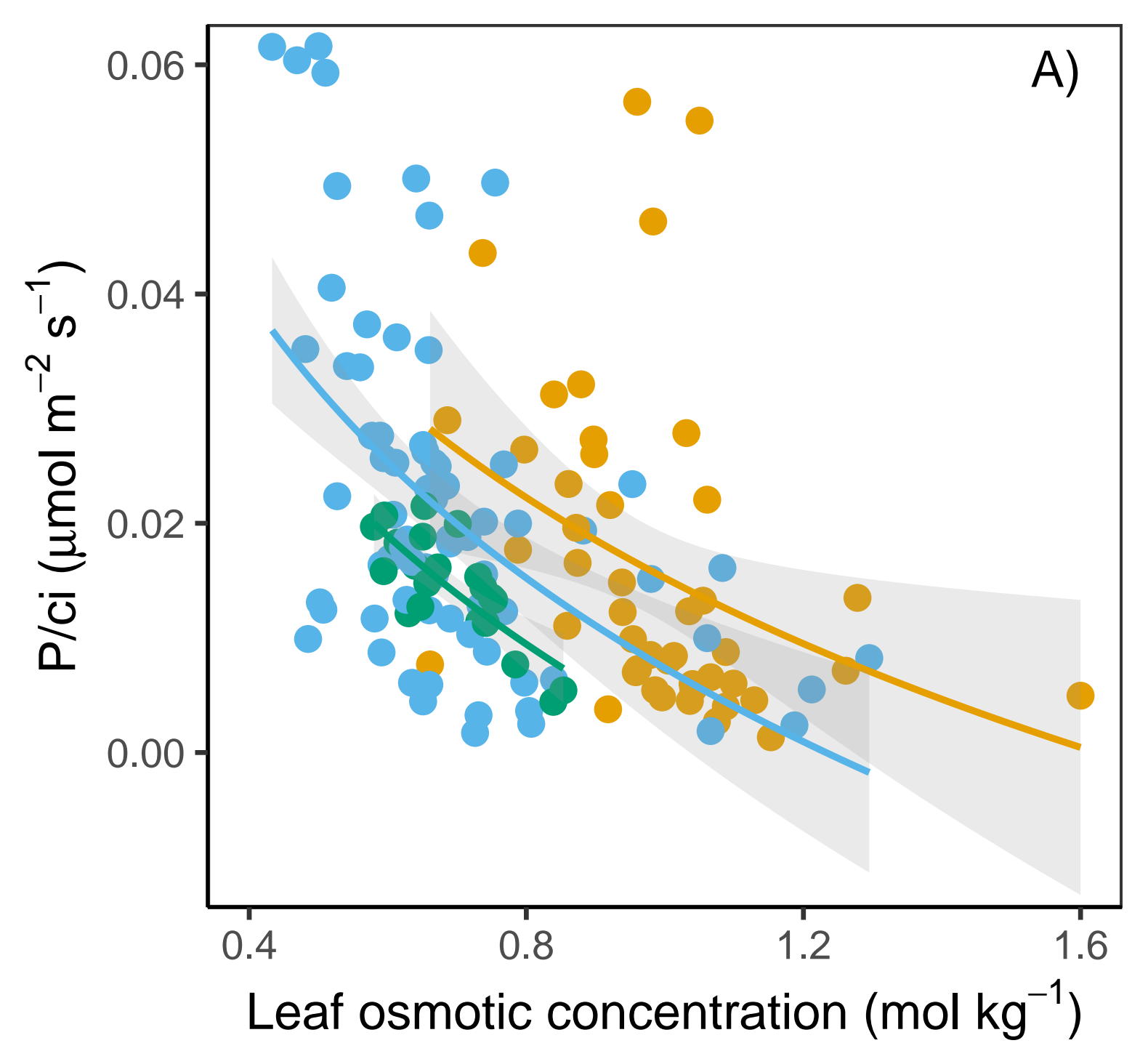




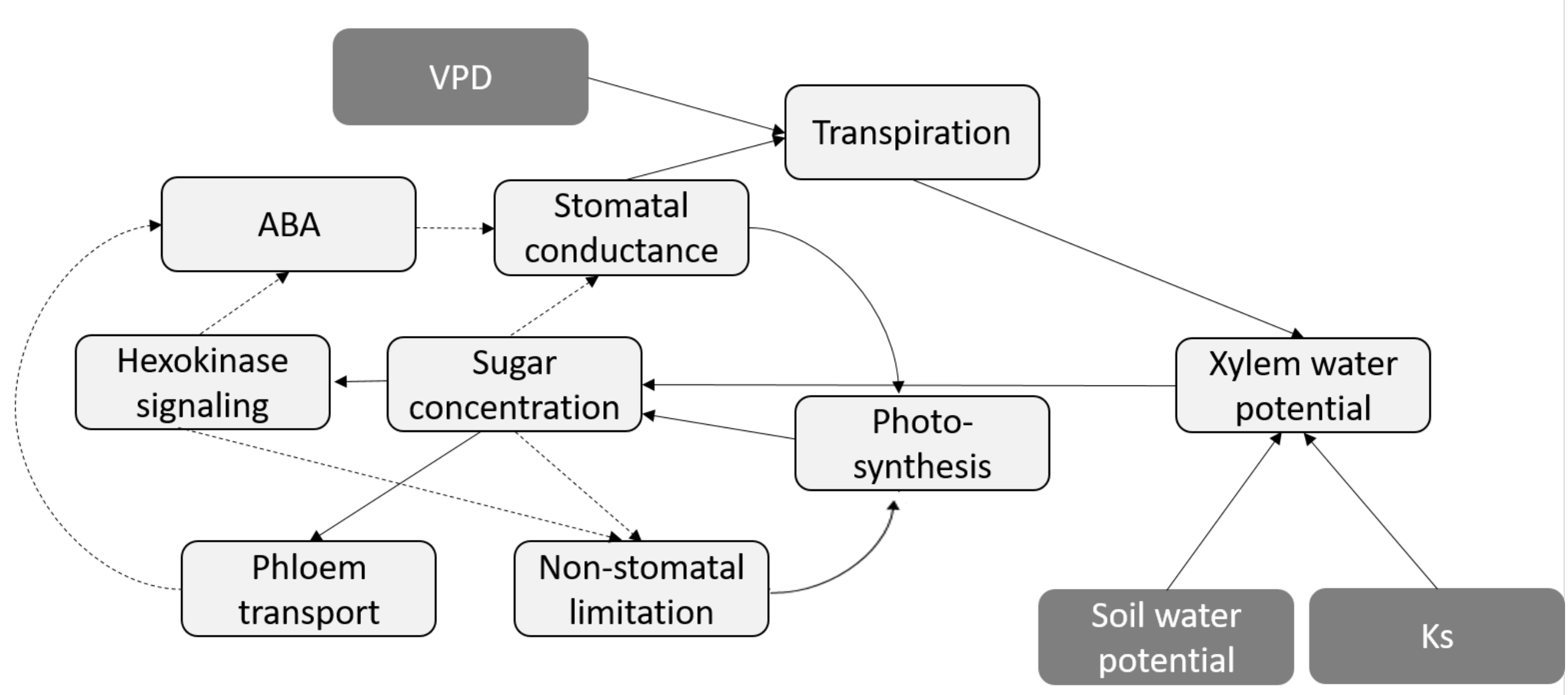




\section{New Phytologist Supporting Information}

Article title: Leaf carbon and water status control stomatal and non-stomatal limitations of photosynthesis in trees.

Authors: Yann Salmon, Anna Lintunen, Alexia Dayet, Tommy Chan, Roderick Dewar, Timo Vesala, Teemu Hölttä

Article acceptance date: Click here to enter a date.

The following Supporting Information is available for this article:

Notes S1 Assessing non-stomatal limitation to photosynthesis.

Fig. S1 The dependence of the ratio of measured to predicted A on leaf osmolality and water potential.

Table S1 Species and treatment (C: control and D: drought) specific exponent of power function fitted to the data from the drought experiment (details of the transformation can be found in table 2).

Table S2 Species specific exponent of power function fitted to the data from the notching experiment (details of the transformation can be found in table 3). Different letters mean statistically different exponents.

Notes S2 Supporting information for testing the predicted relationship between $g_{s}$ and $K_{s}$

Fig. S2 median, first and third quantiles (upper and lower hinges, upper and lower whisker are the highest and lowest, respectively, values no further from the hinges than 1.5 time to interquantile distance) of $K_{s l}$ during the drought experiment.

Table S3 Best-fit parameters $a$ and $b$ in eqn (S2.3) for the Medlyn et al. (2011) and Dewar et al. (2018) models for the drought and notching experiments.

Notes S2 Showing the mathematical equivalence between testing the relation between $r / r_{m}$ and $E$ and the relation between $g_{s}$ and $K_{s l}$ 


\section{Notes S1 Assessing non-stomatal limitation to photosynthesis.}

To confirm the validity of the use of photosynthetic efficiency $\left(P / C_{i}\right)$ as a proxy for the effect of non-stomatal limitation to photosynthesis, we used $A-c_{i}$ curves measured prior to notching to predict the expected $A$ for any given $c_{i}$ if non-stomatal limitations to photosynthesis (i.e. photosynthetic efficiency) remained constant. We then compared the measured $A$ to the predicted $A$ for that given $c_{i}$. Hence, changes in stomatal conductance, i.e. changes in the supply of $\mathrm{CO}_{2}$ to the substomatal cavity, cannot be responsible for the changes in A. A similar approach was used by Drake et al. (2017). Fig S1 demonstrates the ratio of $A$ measured to $A$ predicted as a function of leaf osmotic concentration and leaf water potential.

The relation between $\log ($ A/Apredicted) against $\log$ (osmotic concentration) was highly significant $(\mathrm{p}<0.0001)$ with no species effect and a small interaction term between species and log(osmolality) ( $\mathrm{p}=0.046$ ). Overall the model marginal $\mathrm{R}^{2}$ was 0.37 and the conditional $\mathrm{R}^{2}$ accounting for the random term (i.e. the experiment identity) was 0.51 .

The relation between $\log ($ A/Apredicted) against $\log (-$ water potential) was highly significant $(\mathrm{p}<0.0001)$ with a species effect $(\mathrm{p}=0.032)$ and no interaction between species and $\log (-$ water potential). Overall the model marginal $\mathrm{R}^{2}$ was 0.53 and the conditional $\mathrm{R}^{2}$ accounting for the random term (i.e. the experiment identity) was 0.75 .

These results are consistent with those obtained from $P / c_{i}$ and thus support the validity of using the changes in photosynthetic efficiency to assess changes in non-stomatal limitations. 

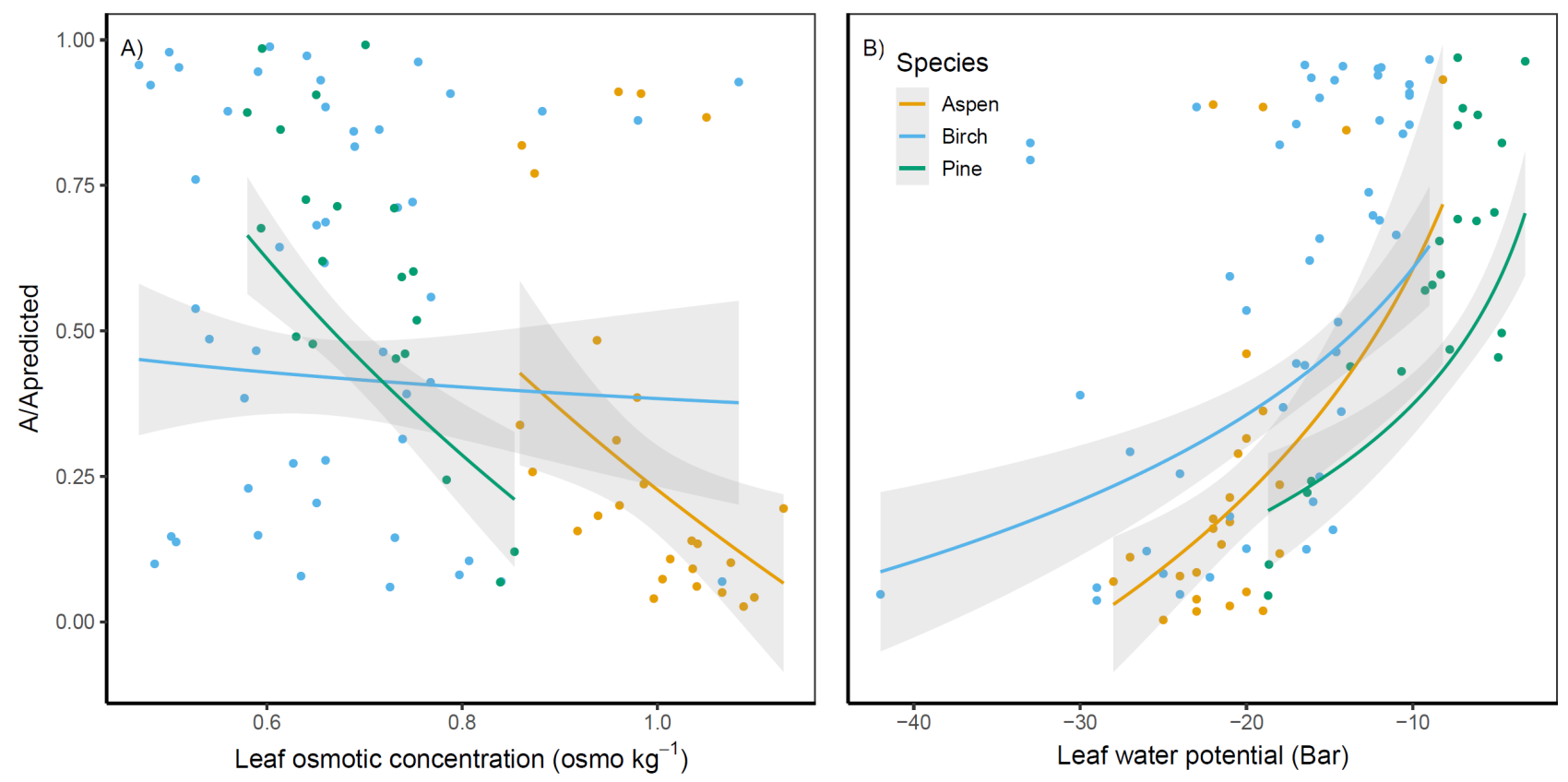

Fig. S1 The dependence of the ratio of measured to predicted A on leaf osmotic concentration and water potential. 
Table S1 Species and treatment (C: control and D: drought) specific exponent of power function fitted to the data from the drought experiment (details of the transformation can be found in table 2). Different letters mean statistically different exponents.

\begin{tabular}{|c|c|c|c|c|c|c|c|c|c|c|}
\hline Species & $P / c_{i}$ & & Vcmax & & Jmax & & $P$ & & $g_{s}$ & \\
\hline $\begin{array}{l}\text { and } \\
\text { treatmen }\end{array}$ & $\begin{array}{r}\text { Osmotic } \\
\text { concentratio }\end{array}$ & $\begin{array}{l}\text { Water } \\
\text { potentia }\end{array}$ & $\begin{array}{l}\text { Osmotic } \\
\text { concentratio }\end{array}$ & $\begin{array}{l}\text { Water } \\
\text { potentia }\end{array}$ & $\begin{array}{l}\text { Osmotic } \\
\text { concentratio }\end{array}$ & $\begin{array}{l}\text { Water } \\
\text { potentia }\end{array}$ & $\begin{array}{l}\text { Osmotic } \\
\text { concentratio }\end{array}$ & $\begin{array}{l}\text { Water } \\
\text { potentia }\end{array}$ & $\begin{array}{l}\text { Osmotic } \\
\text { concentratio }\end{array}$ & $\begin{array}{l}\text { Water } \\
\text { potentia }\end{array}$ \\
\hline $\mathrm{t}$ & $\mathrm{n}$ & 1 & $\mathrm{n}$ & 1 & $\mathrm{n}$ & 1 & $\mathrm{n}$ & 1 & $\mathrm{n}$ & 1 \\
\hline Aspen & $-0.054^{\mathrm{a}}$ & $-0.010^{\mathrm{a}}$ & $-1.98^{\mathrm{a}}$ & $-0.046^{\mathrm{a}}$ & $-1.72^{\mathrm{a}}$ & $-0.062^{\mathrm{a}}$ & $-4.62^{a}$ & $-1.11^{\mathrm{a}}$ & $-4.38^{\mathrm{a}, \mathrm{b}}$ & $-0.98^{\mathrm{a}}$ \\
\hline Birch & $-0.080^{\mathrm{a}}$ & $-0.008^{\mathrm{a}}$ & $-2.29^{a}$ & $0.203^{\mathrm{a}}$ & $-1.76^{\mathrm{a}}$ & $0.086^{\mathrm{a}}$ & $-4.65^{a}$ & $-1.27^{\mathrm{a}}$ & $-6.74^{\mathrm{b}}$ & $-2.00^{\mathrm{a}}$ \\
\hline Pine & $-0.023^{b}$ & $-0.012^{\mathrm{a}}$ & $-1.39^{\mathrm{a}}$ & $-0.297^{\mathrm{a}, \mathrm{b}}$ & $-1.19^{\mathrm{a}}$ & $-0.219^{\mathrm{a}, \mathrm{b}}$ & $-2.25^{\mathrm{a}, \mathrm{b}}$ & $-1.05^{\mathrm{a}}$ & $-2.66^{\mathrm{a}}$ & $-1.37^{\mathrm{a}}$ \\
\hline Spruce & $-0.010^{b}$ & $-0.007^{a}$ & $-1.99^{a}$ & $-0.734^{b}$ & $-1.37^{a}$ & $-0.729^{b}$ & $-2.32^{b}$ & $-1.64^{\mathrm{a}}$ & $-0.13^{\mathrm{c}}$ & $-1.79^{a}$ \\
\hline
\end{tabular}


Table S2 Species specific exponent of power function fitted to the data from the notching experiment (details of the transformation can be found in table 3). Different letters mean statistically different exponents.

\begin{tabular}{|c|c|c|c|c|c|c|c|}
\hline & $\begin{array}{l}P / c_{i} \\
\text { Osmotic } \\
\text { concentration }\end{array}$ & $\begin{array}{l}P / c_{i} \\
\text { water potential }\end{array}$ & $\begin{array}{l}P / c_{i} \\
\mathrm{~g}_{\mathrm{s}}\end{array}$ & $\begin{array}{l}P \\
\text { Osmotic } \\
\text { concentration }\end{array}$ & $\begin{array}{l}P \\
\text { water potential }\end{array}$ & $\begin{array}{l}g_{s} \\
\text { Osmotic } \\
\text { concentration }\end{array}$ & $\begin{array}{l}g_{s} \\
\text { water potential }\end{array}$ \\
\hline Aspen & $-0.027^{a}$ & $-0.013^{a}$ & $0.018^{\mathrm{a}}$ & $-1.84^{\mathrm{a}}$ & $-1.00^{\mathrm{a}}$ & $-1.72^{\mathrm{a}}$ & $-0.87^{\mathrm{a}, \mathrm{b}}$ \\
\hline Birch & $-0.027^{a}$ & $0.007^{\mathrm{b}}$ & $0.016^{\mathrm{a}}$ & $-2.36^{\mathrm{b}}$ & $-0.28^{\mathrm{a}}$ & $-2.59^{b}$ & $0.39^{a}$ \\
\hline Pine & $-0.042^{\mathrm{b}}$ & $-0.024^{\mathrm{a}}$ & $0.010^{\mathrm{b}}$ & $-2.28^{\mathrm{a}, \mathrm{b}}$ & $-1.05^{\mathrm{a}}$ & $-2.43^{\mathrm{a}, \mathrm{b}}$ & $-1.32^{\mathrm{b}}$ \\
\hline
\end{tabular}


Note S2: Supporting information for testing the predicted relationship between $g_{s}$ and $K_{s l}$

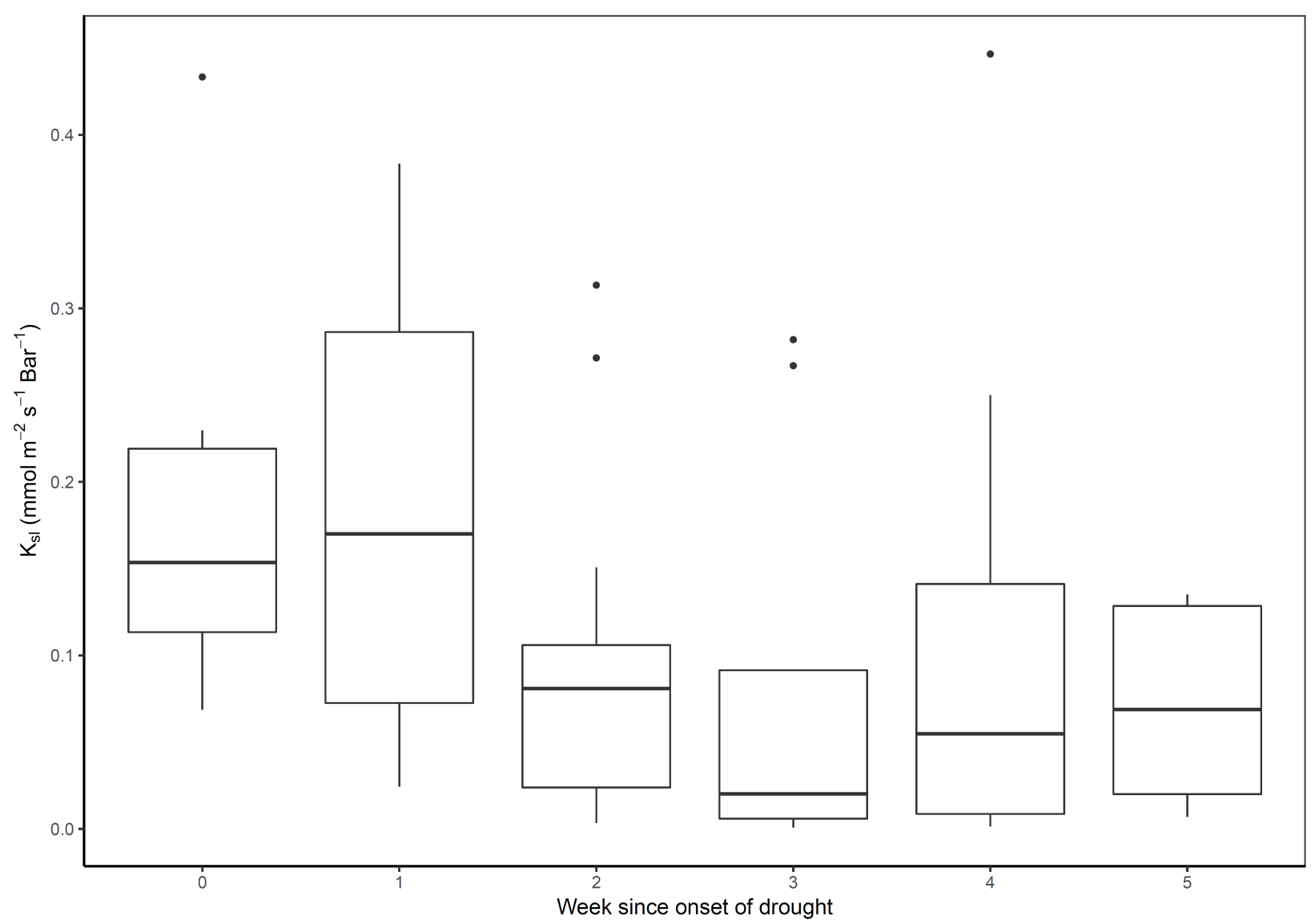

Figure S2: median, first and third quantiles (upper and lower hinges, upper and lower whisker are the highest and lowest, respectively, values no further from the hinges than 1.5 time to interquantile distance) of $K_{s l}$ during the drought experiment.

To compare the prediction of our model (Dewar et al. 2018) with the prediction of the Medlyn et al. (2011) model, for each model we tested the linearity between the predicted and measured $g_{s}$.

The model of Medlyn et al. (2011) predicts that

$g_{s}=g_{1} \frac{P}{\sqrt{x}}$ 
The corresponding prediction of the model of Dewar et al. (2018) is

$g_{s}=g_{2} \frac{P}{c_{a} \sqrt{D}} \sqrt{K_{s l}}$

where $K_{s l}$ is soil-to-leaf hydraulic conductance, and $g_{2}$ is a known function of physiological parameters (i.e. not an empirical parameter like $g_{1}$ ), and treated here as a constant. This is eqn (4) of the main text.

To evaluate the linearity between predicted and measured $g_{s}$, for each model we selected the values of parameters $a$ and $b$ in the relation

$g_{s, \text { predicted }}=a\left(g_{s, \text { modelled }}\right)^{b}$

that minimized the distance between the measured points and the model prediction (using the nls function in $\mathrm{R}$ ). The closer $b$ is to 1 , the more linear is the relation.

Table S3 shows that in both the notching and drought experiments, linearity was greater for the Dewar et al. (2018) than for the Medlyn et al. (2011) model, particularly so in the drought experiment.

\section{References}

Dewar R, Mauranen A, Mäkelä A, Hölttä T, Medlyn B, Vesala T. 2018. New insights into the covariation of stomatal, mesophyll and hydraulic conductances from optimization models incorporating nonstomatal limitations to photosynthesis. New Phytologist 217(2): 571-585.

Medlyn BE, Duursma RA, Eamus D, Ellsworth DS, Prentice IC, Barton CVM, Crous KY, De Angelis P, Freeman M, Wingate L. 2011. Reconciling the optimal and empirical approaches to modelling stomatal conductance. Global Change Biology 17(6): 2134-2144.

Table S3: Best-fit parameters $a$ and $b$ in eqn (S2.3) for the Medlyn et al. (2011) and Dewar et al. (2018) models for the drought and notching experiments.

\begin{tabular}{llll}
\hline \multirow{2}{*}{ Drought } & Medlyn & \multicolumn{2}{c}{$b$} \\
\cline { 3 - 4 } Notching & $2.10^{-4}$ & 0.68 \\
& Dewar & $3.010^{-5}$ & 0.94 \\
Medlyn & $4.510^{-3}$ & 0.79
\end{tabular}


Note S3: Showing the mathematical equivalence between testing the relation between $r / r_{m}$ and $E$ and the relation between $g_{s}$ and $K_{s /}$.

Equation 4 shows the relation between $g_{s}$ and $K_{s l}$

$$
g_{s} \approx \frac{A}{c_{a}} \frac{\xi}{\sqrt{D}} \propto \frac{A}{C_{a}} \sqrt{\frac{K_{s l}}{D}} .
$$

$K_{s l}$ can be expressed as:

$$
K_{s l}=\frac{E}{\Delta \Psi},
$$

Thus, replacing $K_{s l}$ in equation 4 by equation 5 gives:

$$
g_{s} \propto \frac{A}{C_{a}} \sqrt{\frac{E}{D * \Delta \Psi}} .
$$

Because $c_{a}$ is constant, the proportionality can be expressed as equation 6:

$$
g_{s} \propto A \sqrt{\frac{E}{D * \Delta \Psi}}
$$

Furthermore: $g_{s}=E / 1.6 D$, thus equation 6 can be written:

$$
\begin{aligned}
& \frac{E}{1.6 D} \propto A \sqrt{\frac{E}{D * \Delta \Psi}} . \\
& \frac{E}{D} \propto A \sqrt{\frac{E}{D * \Delta \Psi}} .
\end{aligned}
$$

By rearranging, we obtain: 
Which gives:

$$
E \propto A^{2} \frac{D}{\Delta \Psi} \equiv r
$$

Because we are looking at the proportionality between both side of the equation, it is also equivalent to test:

$$
E \propto r / r_{m}
$$

